\title{
Evaluation for the continent of Australia of the simulation of the surface climate using the Biosphere/Atmosphere Transfer Scheme (BATS) coupled into a global climate model $^{*}$
}

\author{
A. Henderson-Sellers \\ School of Earth Sciences, Macquarie University, North Ryde, New South Wales 2109, Australia
}

\begin{abstract}
The Biosphere Atmosphere Transfer Scheme (BATS) of Dickinson et al. (1986) has been coupled to the National Center for Atmospheric Research's Community Climate Model (CCM1). The land surface climatology generated by averaging the results of a 3 yr model integration on a monthly basis is evaluated for the continent of Australia by comparison with published descriptions of a wide range of parameters. The major inconsistencies in the BATS simulation are associated with surface hydrology: modelled precipitation is too high in the central desert area and the large maxima of rainfall on the coast are grossly underestimated. This may be entirely a result of the coarse resolution of the GCM grid but, since rainfall is of crucial importance to agricultural and water supply activities, the inconsistencies clearly merit further consideration. Further problems associated with the surface hydrological regime include the difficulty of comparing total modelled evapotranspiration with evaporation calculated from evaporation pan measurements. In a semi-arid to arid environment such as Australia the latter are gross overestimates. Other differences between the BATS climate and measurements are confined to the central desert area and the crop and short grass regions in the south: simulated maximum temperatures are too high in the desert and minimum temperatures marginally too high in the southeast. Surface net radiation appears to be underestimated in the desert by up to $50 \mathrm{~W}$ $\mathrm{m}^{-2}$ (probably due to the combined effect of overestimated temperatures and, more importantly, overestimated cloud amounts). Some of these secondary inconsistencies could be partially the result of the poor simulation of surface hydrological regimes which, in turn, seems likely to be primarily the fault of the coarse spatial resolution of the model. Proposals are outlined for improved methods of validation and testing the predictions of such complex biospheric submodels, at least at continental scale.
\end{abstract}

\section{INTRODUCTION}

The land surface is the locus of practically all of mankind's food-growing and water-gathering activities. If climate is likely to change then the effects of change will be most keenly felt if they manifest themselves in terms of changes in the land surface climatology. To date, continental surface climates have been neglected by climate modellers: the parameterization of the land surface is highly simplistic in most atmospheric general circulation climate models (AGCMs)

\footnotetext{
- This material is derived primarily from an invited review paper entitled 'The coming of age of land surface climatology' in a special issue of the journal Global and Planetary Change
}

and evaluation of the present-day continental surface climate usually consists of perfunctory comparisons of temperatures and precipitation. Whilst it is acknowledged that satisfactory simulation of the features of the general circulation of the atmosphere is an essential prerequisite for climate modelling it now seems timely to begin to consider the adequacy of the land surface climate simulated by such models.

Recently efforts have been made to improve the parameterization of the land surface in AGCMs. Only 3 land surface schemes which include explicit canopy calculations have so far been coupled into AGCMs; these are the simple biosphere model (SiB) of Sellers et al. (1986), BEST (Bare Essentials of Surface Transfer) (Pitman 1988) and the Biosphere Atmosphere Transfer Scheme (BATS) of Dickinson et al. (1986). It is the latter 
scheme, BATS, coupled into a host AGCM, the NCAR Community Climate Model (NCAR-CCM; Version 1) which has been used for this experiment.

BATS has been extensively tested in a stand-alone mode (e.g. Wilson et al. 1987a) and has been used to examine the climate of tundra regions (Wilson et al. 1987b) and the impact of Amazonian tropical deforestation (Dickinson \& Henderson-Sellers 1988) by coupling it into the previous version of the CCM (CCMOB). Here a different method of evaluation is explored. A 3 yr integration of NCAR-CCM + BATS has given rise to monthly means of a large number of surface climate parameters. The 22 grid elements which encompass the continent of Australia have been extracted from these global fields and are evaluated here by comparison with observations.

\section{THE BATS SURFACE PACKAGE AND THE CCM}

BATS can treat 18 different surface types and vegetation covers (Fig. 1a). At a given grid point, a seasonally dependent fraction of surface covered by vegetation is specified; the remaining fraction is assumed to be covered by bare soil. The fractional vegetation cover varies seasonally, but is now based on a crude assumption of a maximum value when the deep soil temperature (see below) is above $298 \mathrm{~K}$ and decreasing in a quadratic fashion to a specified minimum value when the deep soil temperature is below $273 \mathrm{~K}$.

Prognostic equations are solved for the temperature of a surface soil layer (about $10 \mathrm{~cm}$ thick) and a deep soil layer (about $1 \mathrm{~m}$ thick) using the force-restore method. This method includes exchanges of radiant, sensible and latent heat between the top soil and the atmosphere, heat release by water-phase changes and diffusion between the top and deep soil layers (Fig. 1b). The soil heat capacity and conductivity depend on the soil type and moisture content. The force-restore method yields accurate surface soil temperatures for a diurnal cycle of soil heating, while the formulation for the deep soil temperature is designed to give a proper response to seasonal forcing.

In the presence of vegetation, the temperatures of canopy air and foliage are calculated diagnostically via an energy balance equation including canopy-ground and canopy-atmosphere radiative and sensible heat exchanges, transpiration from stomatal pores and evaporation of moisture deposited on the leaves by interception of precipitation or dew formation. The transpiration rate is calculated using a foliage-resistance formulation which includes the contributions of the aerodynamic resistance to moisture and heat flux of the foliage molecular boundary layer and the total mechanical resistance encountered by diffusion from inside a leaf to outside (or stomatal resistance). The stomatal resistance depends on the incoming solar radiation and the leaf temperature and is modified to account for the root resistance to soil water uptake by the plants

Predictive equations are solved for the water content in the top and deep soil layers. These include the contributions of precipitation, leaf drip from the canopy foliage, evapo-transpiration, surface and groundwater runoff and diffusive exchange of water between soil layers. These equations are a parameterized formulation obtained from a fit to results from a high resolution soil model (Dickinson 1984).

The scheme incorporates snow, frozen soil water and related phase changes. A prognostic equation is solved for the average snow cover (in mm of liquid water) at a given grid point. This equation includes precipitation, sublimation and snow melt. The fraction of surface covered by snow is diagnostically calculated from the average snow cover at the grid point and the roughness length of vegetation or bare soil.

For each vegetation type, vegetation albedos are specified for the ultraviolet/visible and near-infrared regions of the solar spectrum. The albedo for bare soil depends on soil colour class and decreases with soil water content. It varies from 0.05 to 0.2 in the ultraviolet/visible region and from 0.1 to 0.4 in the near-infrared region. The albedos for diffuse radiation are assumed to be the same as those for direct radiation. At a given grid point, the surface albedo is obtained by averaging over vegetated, bare soil and snow-covered areas. The soil and vegetation infrared emissivity is set equal to 1.

Sensible heat, water vapour and momentum fluxes at the surface are calculated from a standard surface drag coefficient parameterization. The drag coefficient for a given grid point is obtained via an average over vegetated, bare soil and snow-covered areas. The drag coefficients are expressed as a neutral drag coefficient times an atmospheric stability correction factor. The neutral drag coefficient is a logarithmic function of the height of the bottom atmospheric model level and the roughness length of vegetation, bare soil, water or snow. The roughness length for different surface types is specified. The stability correction factor is assumed to be the same for momentum, heat and water vapour transfer and is expressed in terms of the local bulk Richardson number. In order to use this drag coefficient parameterization, the bottom atmospheric level should not exceed a few tens of metres

When coupled to a meterorological or climate 'host' model, the vegetation type, soil texture and soil colour need to be specified for each grid point, along with the initial snow cover, soil moisture and ground and foliage temperatures. From the host model then, BATS 
(a)

Fig. 1. (a) BATS can represent a wide range of different land surface types. Four land surface types are shown to illustrate the flexibility of the parameterization of the land-surface scheme. The variation in the fraction of cover by vegetation of the soil surface is shown by (i) the relative width of the 'plant' compared with the soil and (ii) the difference between the 'leaf' extents shown on the left-hand side of the 'plant'; the latter shows the temperature-dependent range in cover. Differences in stomatal resistance are shown, schematically, by different size stomata on the right-hand side of the 'plant'. The height of the 'plant' indicates the vegetation roughness length except that the tropical forest is shown extending to only half the prescribed roughness length and the width of the 'stem' indicates the relative importance of stems and dead matter in the ground cover. In addition, albedos (solar and near-infrared), leaf area index, foliage resistance to wind and plant sensitivity to photosynthetically active radiation are parameterized. (b) BATS includes full energy and hydrological budgets and modifies the momentum interchange with the atmosphere

(b)
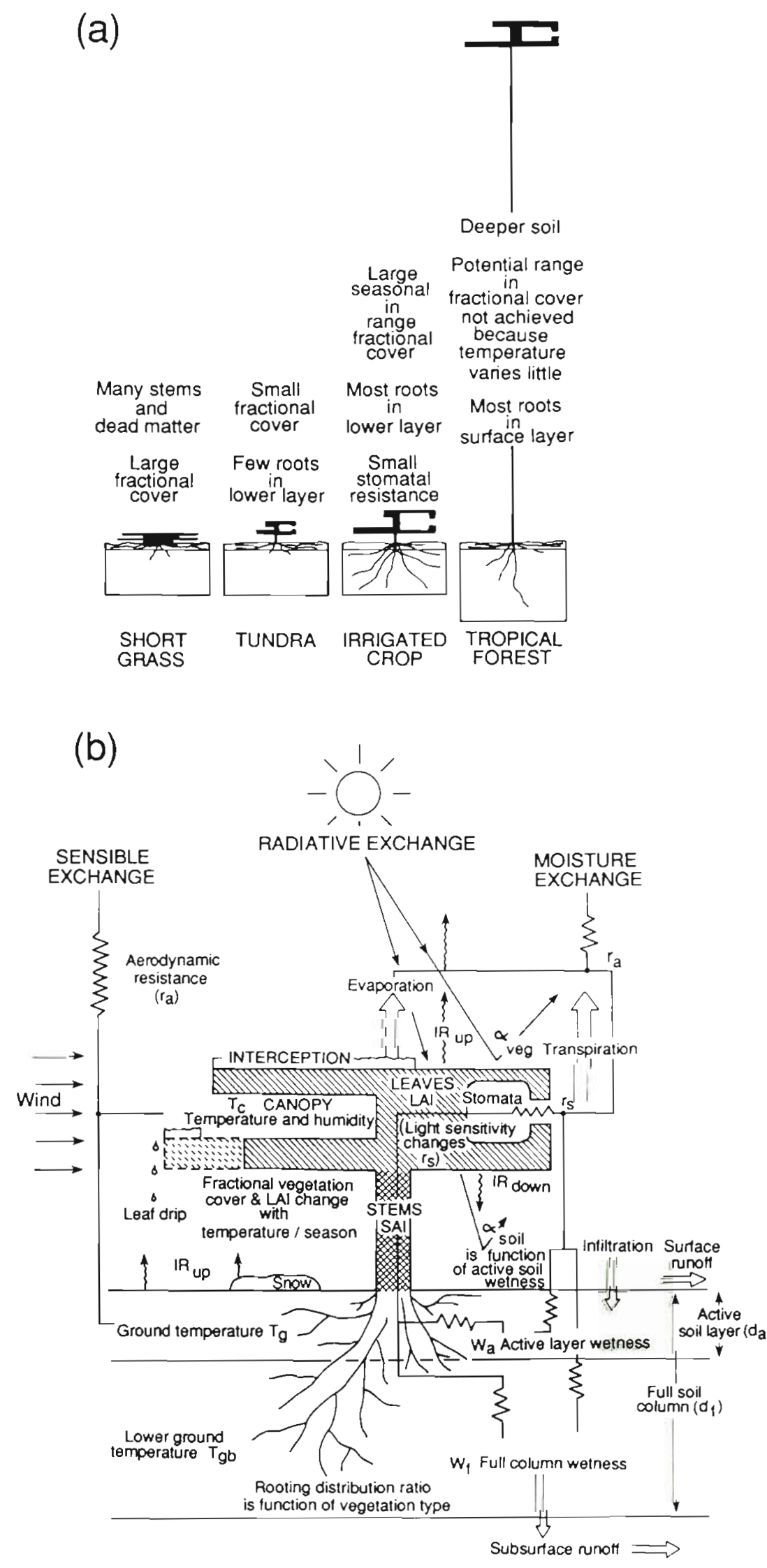
requires as input wind components, air density, temperature and water vapour mixing ratio at the bottom model level, surface radiant fluxes at solar and infrared wavelengths and precipitation. From these and other internally generated quantities, BATS calculates temperatures of surface soil, deep soil, canopy foliage and canopy air, the surface and deep soil moisture, snow cover and surface fluxes of momentum, heat and moisture. The surface fluxes are then fed into the momentum, thermodynamics and water vapour equations of the host model as lower boundary conditions.

The NCAR Community Climate Model Version 1 (CCM1) was originally based on the Australian spectral model of Bourke et al. (1977) and has evolved over a decade or so. The model is thoroughly documented (the most recent manifestation, Version 1, is described by Williamson et al. 1987) and is widely used for climatic simulations of monthly to multidecadal time scales. CCM1 is a global atmospheric circulation model with primitive equations formulated in a spherical co-ordinate spectral space and in finite grid vertical layers employing the $\sigma$ co-ordinate system. The integrations used for this analysis were undertaken with the standard truncation at wave number 15 (R15) giving rise to a grid size of ca $7.5^{\circ}$ longitude by $4.5^{\circ}$ latitude and with 12 layers in the vertical.

The CCM, in common with most state-of-the-art global climate models, reproduces the major features of the general circulation and global climate quite well (Williamson \& Williamson 1987). The climatological regime in the Australian region is also adequately represented. For example, the seasonal regimes associated with the movement of the intertropical convergence zone (ITCZ) are fairly well simulated: there is a tendency for pressures to be low in North Australia in January which coincides with the time at which the ITCZ lies across the Gulf of Carpentaria, during the Australian Monsoon season. In July pressures are higher in the north and the surface wind fields are controlled by the easterly trade winds in the north and the midlatitude westerlies in the south. The simulated surface wind fields in January include a westerly 'monsoon' flow in the north and weak easterly regimes elsewhere as the midlatitude westerly flow is well to the south of the continent. Overall, the regional pressure and wind flow regimes are adequately simulated by the AGCM. The rest of this paper examines the adequacy of the predicted continental surface climate.

\section{BATS SOIL AND VEGETATION TYPES FOR AUSTRALIA}

Fig. 2 shows the BATS/CCM vegetation and soil types classification for Australia. The grid is that gener-

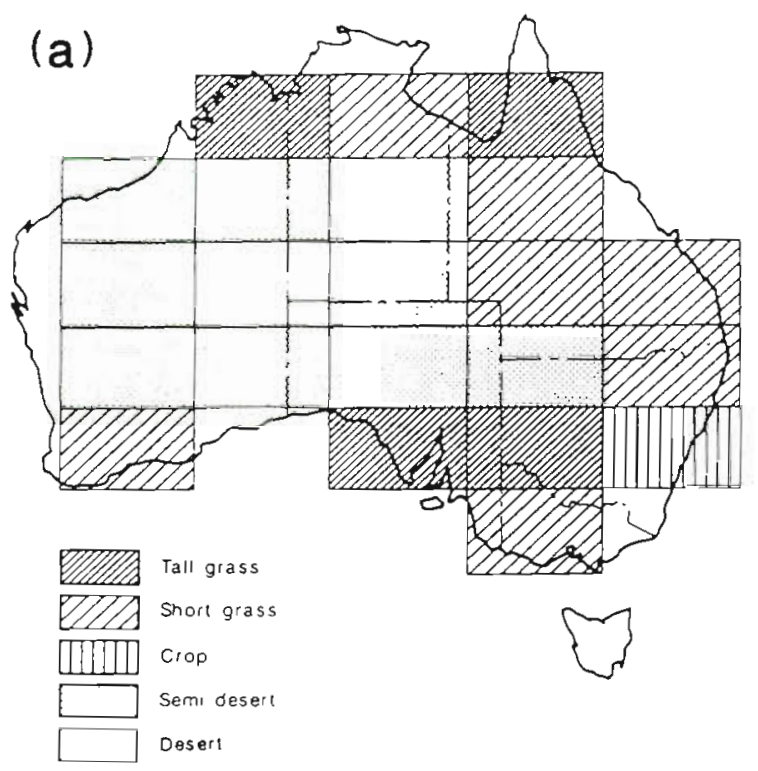

(b) Textures

2 = fine sand to 8 = clayey loam

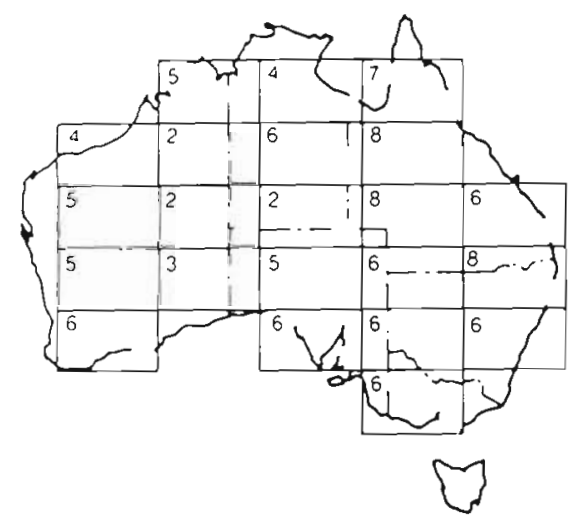

(c) Soil colour $1=$ light to $4=$ medium

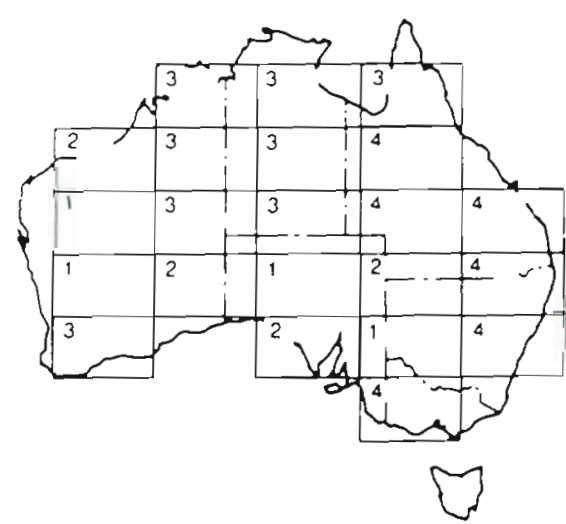

Fig. 2. (a) The NCAR CCM R15 grid elements $\left(4.5^{\circ}\right.$ latitude $x$ $7.5^{\circ}$ longitude) for Australia showing the BATS vegetation classification (see Table 2). (b) BATS soil texture classification for Australia (see Table 1a). (c) BATS soil colour classification. for Australia (see Table 1b) 
ated by the rhomboidal 15 truncation $\left(4.5^{\circ}\right.$ latitude $x$ $7.5^{\circ}$ longitude) of this spectral AGCM. There are thus 22 grid squares on the continent of Australia.

Fig. 2b, c show the soil texture and colour classes assigned from a global data archive of soil colour, texture and drainage described by Wilson \& Henderson-Sellers (1985). Soil colours are all between the lightest class and the middle class although, somewhat surprisingly, the lightest colour classes do not coincide with all the desert areas. The full texture classification used with BATS runs from a coarse sand, texture 1, to a fine clay, texture 12 . Of these classes only 2 (fine sand) to 8 (clayey loam) are used in the Australian region. The soil parameters associated with these colour and texture classes are listed in Table 1.

The global vegetation classification was generated from 3 ecological data sets: Matthews (1983), Wilson \& Henderson-Sellers (1985) and Olson et al. (1983); the latter being $1 / 2^{\circ} \times 1 / 2^{\circ}$ and the other two $1^{\circ} \times 1^{\circ}$ archives. BATS uses 18 distinct vegetation types only 5 of which appear in Australia: desert, semi-desert, crop, short grass and tall grass. The vegetation parameters associated with these classes are listed in Table 2. The BATS vegetation description is an attempt to combine natural vegetation and agricultural development. It is therefore necessary to compare Fig. 2a with maps of 'climax' vegetation (the idealized, final stage of vegetation/ ecological succession in a constant, specified climate) (Fig. 3a) and agriculture (Fig. 3b).

The regions of desert plus semi-desert are adequately represented both in areal extent and position.
The area of 'crop' vegetation in central New South Wales is also a satisfactory representation of agricultural development. The areas designated as short grass correspond to regions of natural vegetation types of woodland and scrub now extensively converted to pasture for sheep and cattle. In the BATS formulation, the 'tall grass' classification is very similar to the 'short grass' class except that a larger roughness length $(0.1$ $\mathrm{m}$ vs $0.02 \mathrm{~m}$ ) is specified and a greater (6 vs 2) leaf area index is possible if temperatures are high (see Table 2). Tall grass in the north of Australia corresponds to regions of woodland and savanna which have been less affected by agricultural development. In the south the tall grass classification seems to correspond to regions of scrub now used for sheep and wheat.

Within the constraints of the very coarse spatial resolution of the climate model grid and the 18 generalized categories, the representation of gross vegetation patterns in Australia is reasonable. Agreement is good with the more generalized vegetation distribution shown in Fig. 3c. It is debatable whether the crop, tall grass, and short grass classes are satisfactory but since these 3 vegetation types differ very little in BATS the important feature is their joint distribution compared with the desert plus semi-desert areas. This is adequate. The lack of any type of trees in Australia seems odd but may be reasonable in view of the coarse spatial resolution and the fact that the 'tall grass' class has the largest roughness length of all the non-tree vegetation types.

It is important to recognize that the soils and vegeta-

Table 1. BATS soil parameters used in Australia

\begin{tabular}{|c|c|c|c|c|c|c|c|}
\hline \multirow[t]{2}{*}{ Parameter } & \multicolumn{7}{|c|}{ Texture class [from fine sand (2) to clayey loam (8)] } \\
\hline & 2 & 3 & 4 & 5 & 6 & 7 & 8 \\
\hline Porosity (volume of voids to volume of soil) & 0.36 & 0.39 & 0.42 & 0.45 & 0.48 & 0.51 & 0.54 \\
\hline Minimum soil suction (m) & 0.03 & 0.03 & 0.2 & 0.2 & 0.2 & 0.2 & 0.2 \\
\hline Saturated hydraulic conductivity $\left(\mathrm{mm} \mathrm{s}^{-1}\right)$ & 0.08 & 0.032 & 0.013 & 0.0089 & 0.0063 & 0.0045 & 0.0032 \\
\hline $\begin{array}{l}\text { Ratio of saturated thermal conductivity to } \\
\text { that of loam } \\
\text { Exponent ' } B \text { ' defined in Clapp \& Hornberger }\end{array}$ & 1.5 & 1.3 & 1.2 & 1.1 & 1.0 & 0.95 & 0.90 \\
\hline$(1978)$ & 4.0 & 4.5 & 5.0 & 5.5 & 6.0 & 6.8 & 7.6 \\
\hline $\begin{array}{l}\text { Moisture content relative to saturation at } \\
\text { which transpiration ceases }\end{array}$ & 0.128 & 0.161 & 0.266 & 0.300 & 0.332 & 0.378 & 0.419 \\
\hline \multicolumn{8}{|l|}{ (b) Functions of colour } \\
\hline \multirow[t]{2}{*}{ Parameter } & \multicolumn{7}{|c|}{ Colour class [from light (1) to medium (4)] } \\
\hline & 1 & 2 & 3 & 4 & & & \\
\hline \multicolumn{8}{|l|}{ Dry soil albedo } \\
\hline$<0.7 \mu \mathrm{m}$ & 0.23 & 0.22 & 0.20 & 0.18 & & & \\
\hline$\geq 0.7 \mu \mathrm{m}$ & 0.46 & 0.44 & 0.40 & 0.36 & & & \\
\hline \multicolumn{8}{|l|}{ Saturated soil albedo } \\
\hline$<0.7 \mu \mathrm{m}$ & 0.12 & 0.11 & 0.10 & 0.09 & & & \\
\hline$\geq 0.7 \mu \mathrm{m}$ & 0.24 & 0.22 & 0.20 & 0.18 & & & \\
\hline
\end{tabular}


Table 2. BATS vegetation types used in Australia

\begin{tabular}{|c|c|c|c|c|c|}
\hline \multirow[t]{2}{*}{ Parameter } & \multicolumn{5}{|c|}{ Land cover/vegetation type } \\
\hline & Crop & Short grass & Tall grass & Desert & Semi-desert \\
\hline Maximum fractional vegetation cover & 0.85 & 0.80 & 0.80 & 0.0 & 0.10 \\
\hline Difference between maximum fractional vege- & & & & & \\
\hline tation cover and cover at temperature $269 \mathrm{~K}$ & 0.6 & 0.1 & 0.3 & 0.0 & 0.1 \\
\hline Roughness length (m) & 0.06 & 0.02 & 0.1 & 0.05 & 0.1 \\
\hline Depth of total soil layer $(m)^{a}$ & 1.0 & 1.0 & 1.0 & 1.0 & 1.0 \\
\hline Depth of upper soil layer $(m)^{d}$ & 0.1 & 0.1 & 0.1 & 0.1 & 0.1 \\
\hline Rooting ratio (upper to total soil layers) & 3 & 8 & 8 & 9 & 8 \\
\hline Vegetation albedo for wavelengths $<0.7 \mu \mathrm{m}$ & 0.10 & 0.10 & 0.08 & 0.20 & 0.17 \\
\hline Vegetation albedo for wavelengths $\geq 0.7 \mu \mathrm{m}$ & 0.30 & 0.30 & 0.30 & 0.40 & 0.34 \\
\hline Minimum stomatal resistance $\left(\mathrm{s} \mathrm{m}^{-1}\right)$ & 150 & 250 & 250 & 250 & 250 \\
\hline Maximum LAl & 6 & 2 & 6 & 0 & 6 \\
\hline Minimum LAI & 0.5 & 0.5 & 0.5 & 0.0 & 0.5 \\
\hline Stem ( $\&$ dead matter) area index & 0.5 & 4.0 & 2.0 & 0.5 & 2.0 \\
\hline Inverse square root of leaf dimension $\left(\mathrm{m}^{-1 / 2}\right)$ & 10 & 5 & 5 & 5 & 5 \\
\hline Light sensitivity factor $\left(\mathrm{m}^{2} \mathrm{~W}^{-1}\right)$ & 0.01 & 0.01 & 0.01 & 0.01 & 0.01 \\
\hline
\end{tabular}

tion classifications for Australia shown in Fig. 2 were arrived at by aggregating information contained in one or more global digital archives with base resolutions of either $1 / 2^{\circ} \times 1 / 2^{\circ}$ or $1^{\circ} \times 1^{\circ}$. The resultant land surface description is thus less than accurate for at least 2 reasons: firstly the original data archives may well not have represented the Australian terrestrial surface especially accurately, and secondly the aggregation process was somewhat arbitrary. The latter problem could, perhaps, be reduced by better aggregation routines although there is some debate at present about whether (and if so how) ecotypes, and soils, which are never dominant at a chosen grid resolution should be represented. The former difficulty is to some extent the fault of the authors of the original global data archives but also reflects the lack of good atlases and surveys for much of Australia.

Surveying and classification are difficult and intensive field operations. In the future, it may be useful to tune the best survey-based ecological and soils classifications by using a vegetation index derived from an operational satellite such as the NOAA AVHRR NDVI (e.g. Tucker et al. 1985, Thomas \& Henderson-Sellers 1987). The BATS scheme already includes code to output a pseudo vegetation index (PVI) constructed from model-computed upwelling (reflected) nearinfrared irradiance minus upwelling (reflected) visible irradiance normalized by their sum, all evaluated at the surface. Fig. 4 illustrates the April and October values of this surface-evaluated PVI. At present the variation seen across the continent is not due to differences in vegetation cover giving rise to differences in the relative reflectivity in the near-infrared vs the visible part of the solar spectrum since BATS specifies a simple factor of 2 increase over visible values to achieve nearinfrared albedos for both soils and vegetation (see Table $1 b$ ). Instead the cross-continent variations in the PVI are caused by a range of factors including the geographical and spectral differences in water vapour absorption, cloud distribution and aerosols which affect the spectral distribution of the downwelling flux at the surface. If, however, BATS' (e.g. Tables $1 \mathrm{~b}$ and 2) parameters included spectrally varying reflectivities and narrow-channel radiation streams were produced by the model, then comparison between model-generated and satellite-derived vegetation indices over an annual cycle could be used to streamline and improve the surface classification process.

Perhaps still more important than the classification of soils and vegetation is the parameterization scheme into which the classified parameters listed in Tables 1 and 2 are fed. Whether the surface processes of the climate system are adequately captured will depend at least as much on the model parameterization as on the exact nature of the original classification. This paper explores the success achieved by the BATS + CCM1 models in representing the land surface climate of Australia.

\section{TEMPERATURES AND SURFACE NET RADIATION}

Comparison of monthly maximum and minimum screen temperatures (Fig. 5 vs Fig. 6) indicates that maximum temperatures are reasonably well simulated except that the maximum temperatures in the desert interior in January are 4 to $6 \mathrm{~K}$ higher than observed. 
Minimum temperatures are similarly reasonably well simulated except that they seem to be slightly high in the southeast. Overall the model results capture both the seasonal and spatial maximum and minimum temperature distributions satisfactorily.

The land surface climate is critically dependent upon the surface radiation budget. Surface net radiation (shortwave-longwave) can be computed from the model (Fig. 7) and evaluated by comparison with estimates of the same parameter (Fig. 8) made by Paltridge (1975). Overall, there is fairly good agreement between these 2 evaluations of net surface radiation except in the central continent in January where the model values are underestimated by ca $50 \mathrm{~W} \mathrm{~m}^{-2}$ (ca $30 \%$ ). One contributing factor might be the model overestimate of surface temperatures in this area in January. However, a 10 to $15^{\circ} \mathrm{C}$ temperature discrepancy would be required to explain all the difference, and a similar underestimation of net surface flux in the central desert also occurs in October when it seems to be unlikely to be due, even partly, to overestimation of temperatures.

An alternative explanation for the model's underestimation of net surface radiation is that cloud cover is being grossly overestimated. Cloud amounts were not readily available for this investigation but a surrogate variable has been plotted for 4 canonical months: Fig. 9 shows the ratio of the surface incident downward shortwavelength radiation to the downward shortwave radiation at the top-of-the-atmosphere. Monthly mean values are generally $>0.7$ except in the southeast and extreme southwest indicating that skies are clear in all the desert and semi-desert areas. Thus the modelled values of net surface radiation seem to be based on reasonable cloud predictions. On the other hand, it must be noted that Paltridge's (1975) evaluations of net surface radiation, which also used cloud amounts as an input variable, incorporated 5 yr of cloud cover observations from only 45 meteorological stations nationwide and included only 3 land surface albedo classes (see Fig. 3c). There is therefore a possibility that, in this instance, the model values are as plausible as this earlier evaluation of net surface radiation.

The BATS scheme computes evaporative and sensible heat fluxes from the surface (Fig. 10). In the east and southeast, evapotranspiration is greatest in January but is still exceeded by the sensible heat flux by ca $50 \mathrm{~W} \mathrm{~m}^{-2}$. A similar pattern occurs in the north and centre of the continent but fluxes are about half of the east coast values. In contrast the west coast maximum in evapotranspiration occurs in July generally exceeding the sensible heat flux by 10 to $20 \mathrm{~W} \mathrm{~m}^{-2}$. Comparison with observed values is hindered by 2 factors: the lack of measurements at a scale similar to the grid element size of the model and the prevalence of evap-

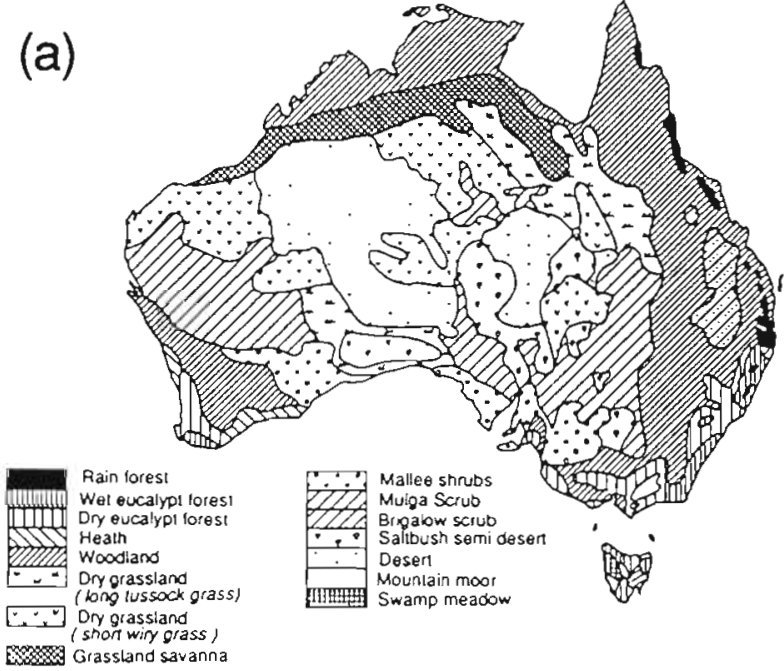

Vegelation map of Auslralia
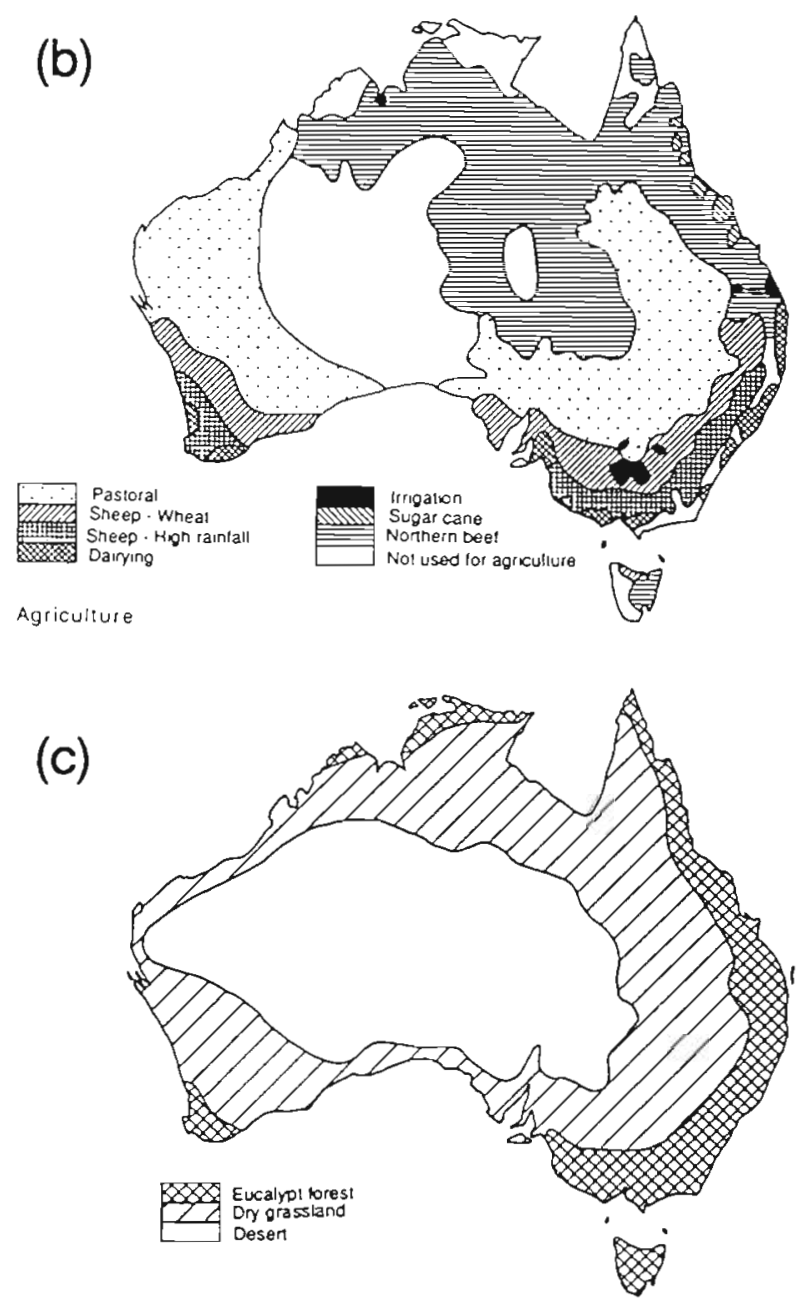

Fig. 3. (a) Natural vegetation of Australia (after Gentilli 1968). (b) Zones of agriculture in Australia (after Sinden 1972 and Linacre \& Hobbs 1977). (c) Generalized vegetation zones (after Paltridge 1975) 

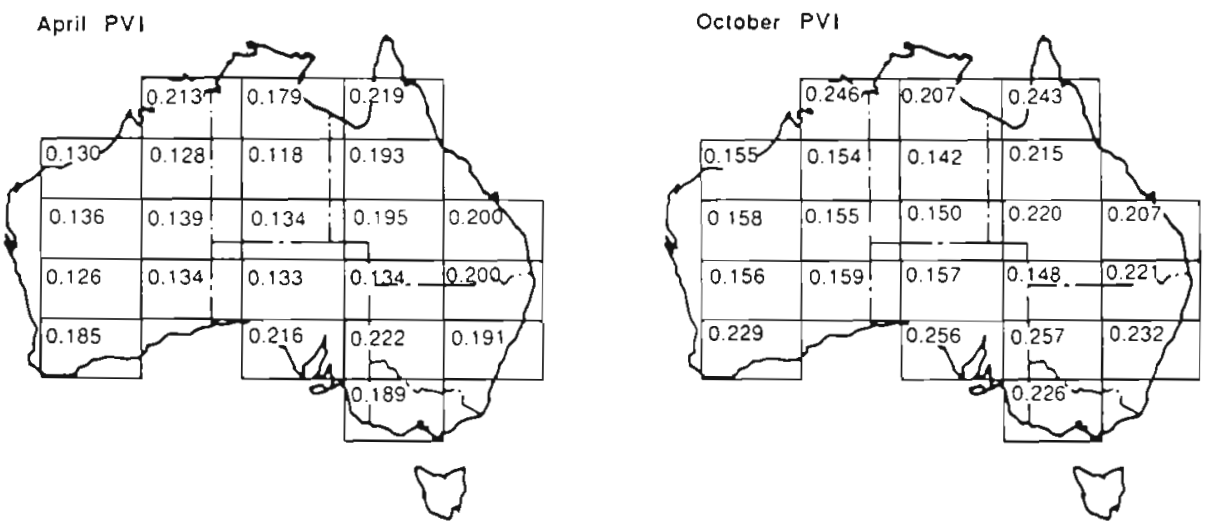

Fig. 4. Model values for April and October of a pseudo-vegetation index (PVI) calculated as the difference between upwelling near infrared and visible irradiances normalized by their sum and evaluated above the canopy
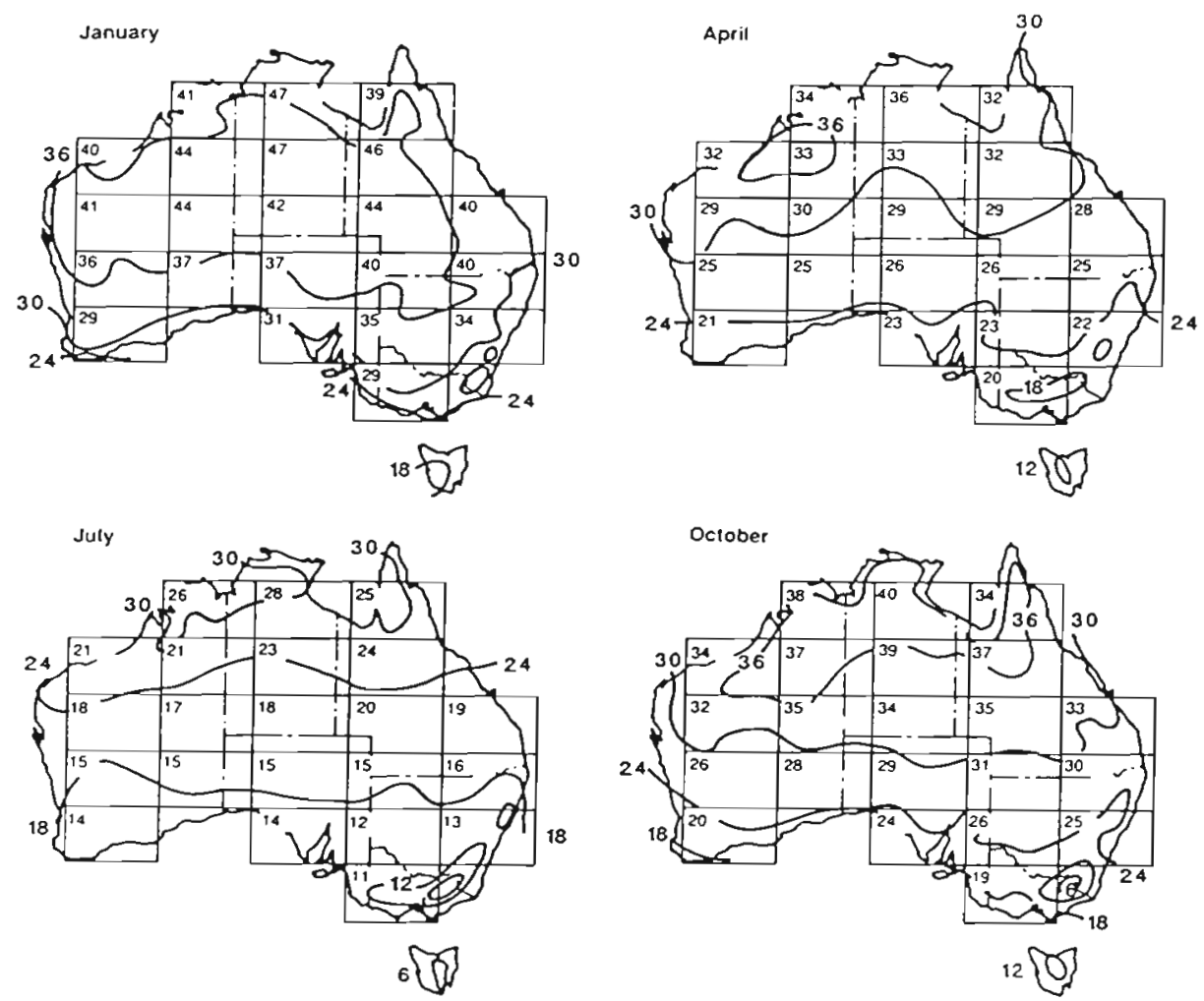

Fig. 5. Modelled values of January, April, July, October monthly maximum screen temperatures $\left({ }^{\circ} \mathrm{C}\right)$ superimposed on contours of observed maximum values. (Observed values taken from Division of National Mapping 1986)

oration pan estimates of evaporation. The latter are extremely high $\left(4000 \mathrm{~mm} \mathrm{yr}^{-1}\right)$ in the central desert region whereas the annual modelled value is ca

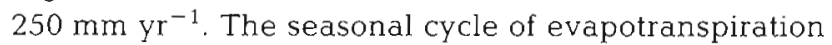
does, however, follow the precipitation pattern as might be expected in a semi-arid region.

One possible test which has not been fully explored is to examine the Bowen ratios (sensible/latent fluxes) in different locations. The modelled values in Fig. 10 give rise to Bowen ratios varying from 2 on the east coast to a maximum of 8 to 10 on the west coast in January but with a much smaller range in July.

\section{PRECIPITATION AND SURFACE HYDROLOGY}

Total annual precipitation for the continent as a whole is correct to first order but the spatial distribution of annual totals (Fig. 11) is very poorly captured by the coarse grid of the CCM. In particular the model fails to simulate the low rainfall in the desert areas, overestimating in the central continent by 50 to 100 mm $\mathrm{yr}^{-1}$ which is $50 \%$ to $70 \%$ of the observed rainfall.

The coastal maxima of rainfall are also underestimated in the model e.g. in the northeast around Cape 
Fig. 6. Modelled values of January, April, July, October monthly minimum screen temperatures $\left({ }^{\circ} \mathrm{C}\right)$ superimposed on contours of observed minimum values. (Observed values taken from Division of National Mapping 1986)
Fig. 7. Modelled surface net radiation $\left(\mathrm{W} \mathrm{m}^{-2}\right)$ for January, April, July, October
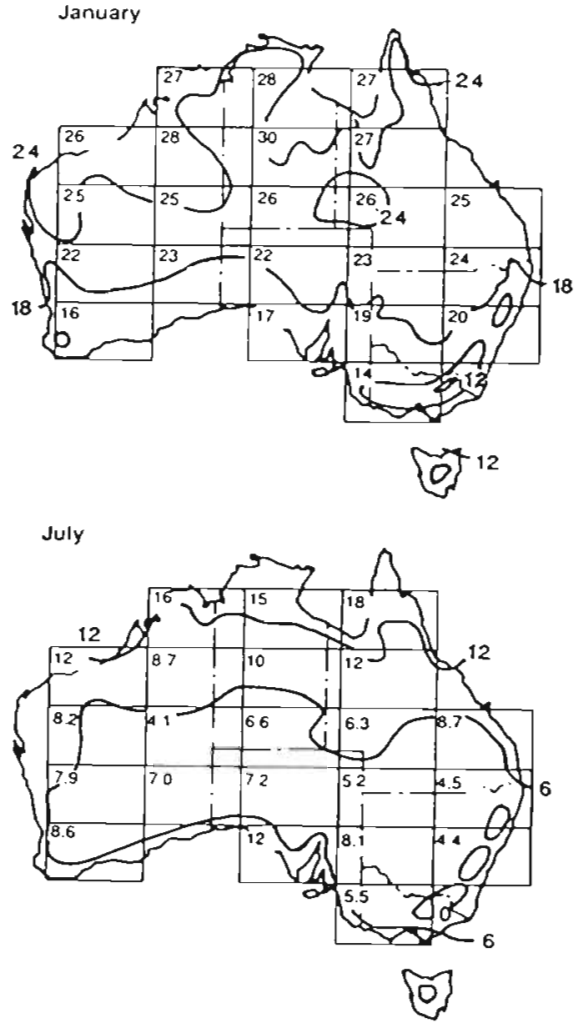

Net surface radiation $\left(W_{m}^{-2}\right)$

January

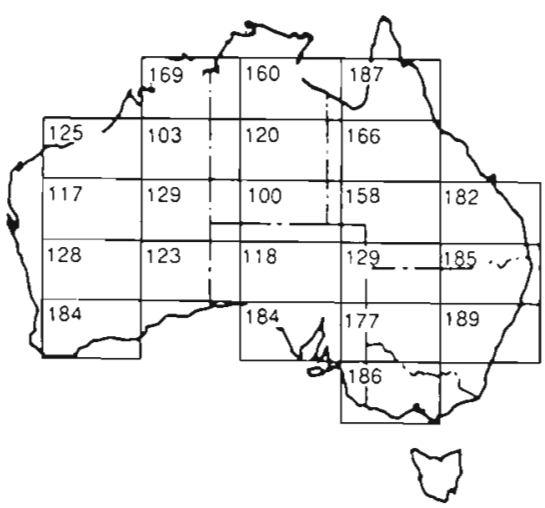

July

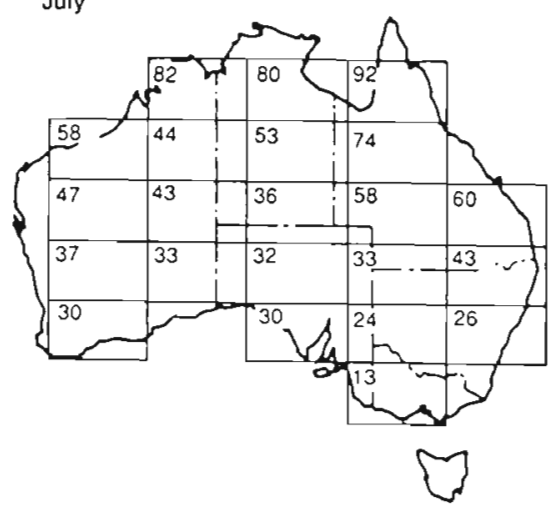

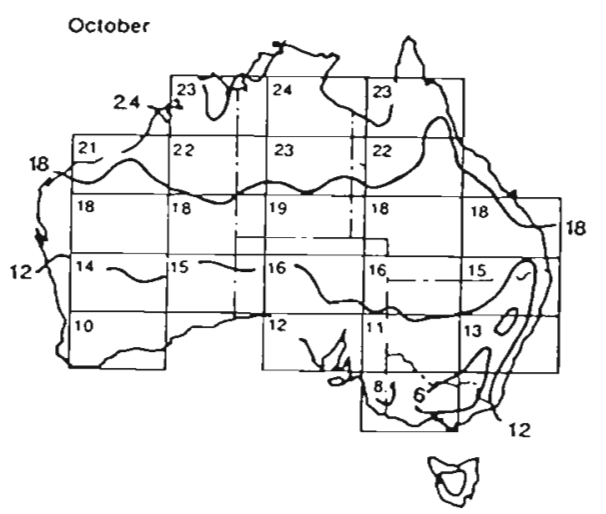
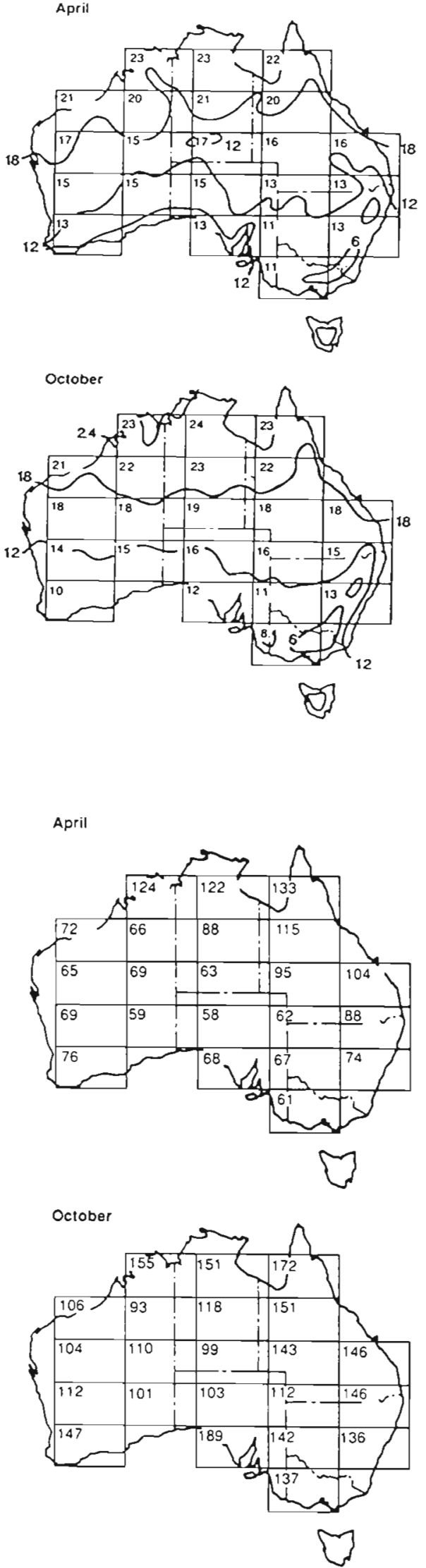

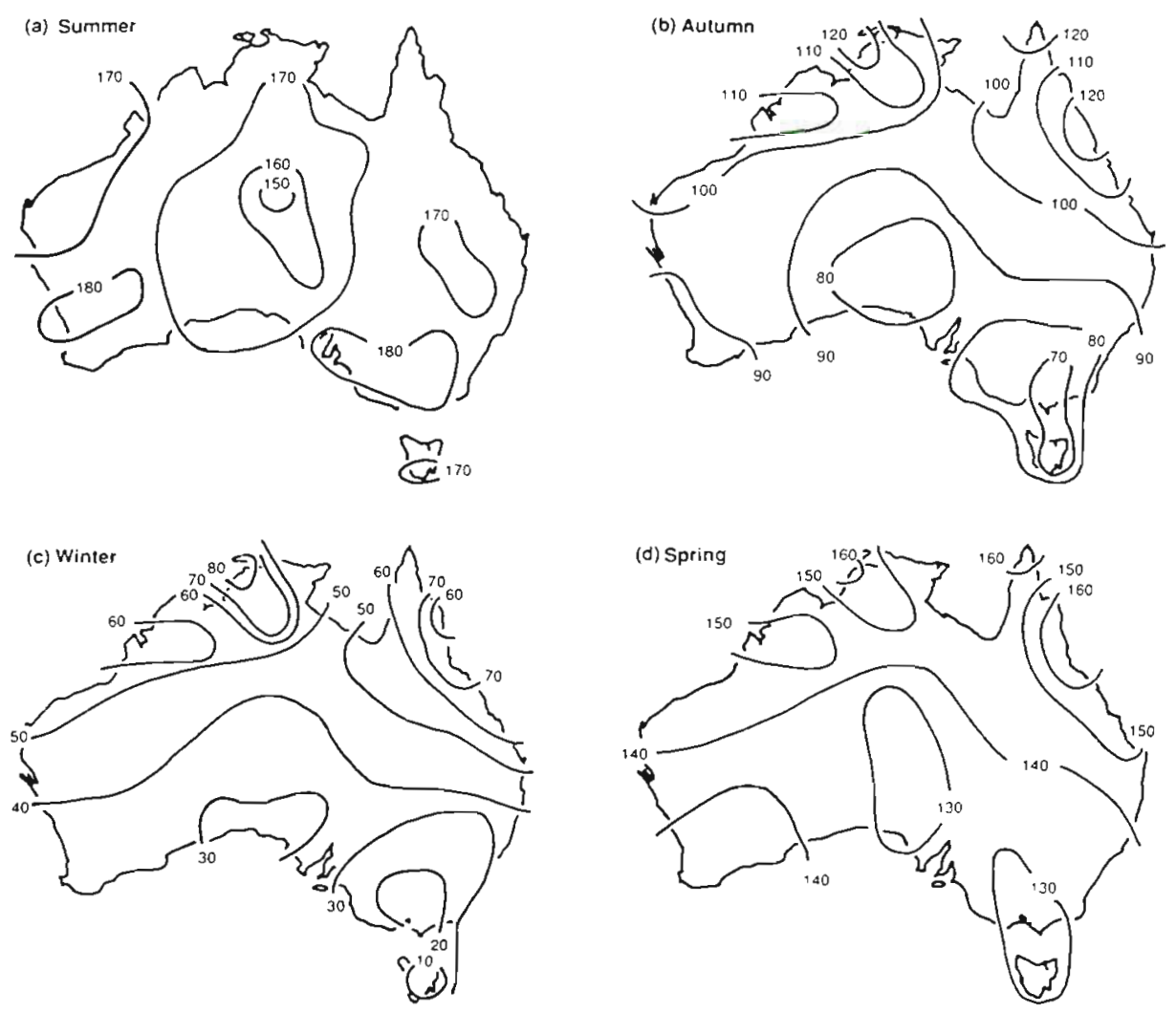

Fig. 8. Calculated surface net radiation $\left(\mathrm{W} \mathrm{m}^{-2}\right.$ ) (redrawn from Paltridge 1975)

Incident solar at surface/top-of-the-atmosphere incident solar

January

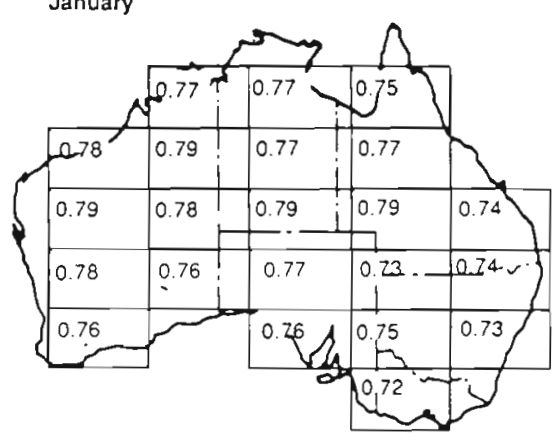

W

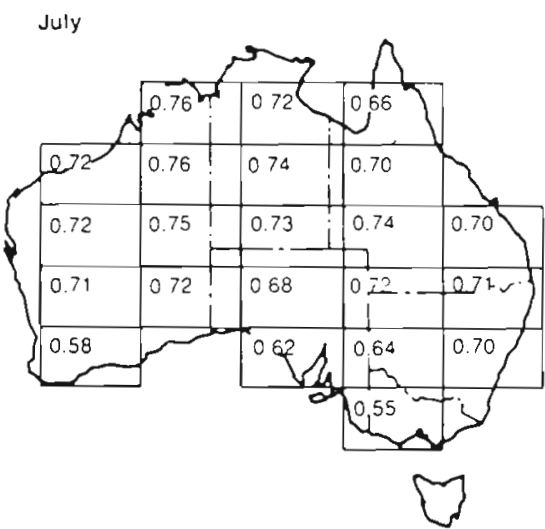

April

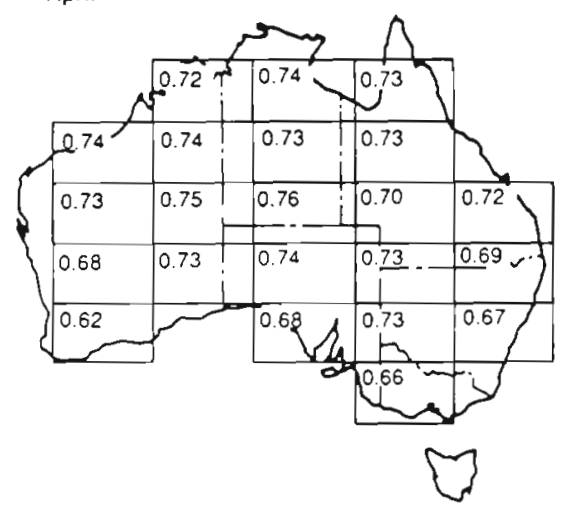

October

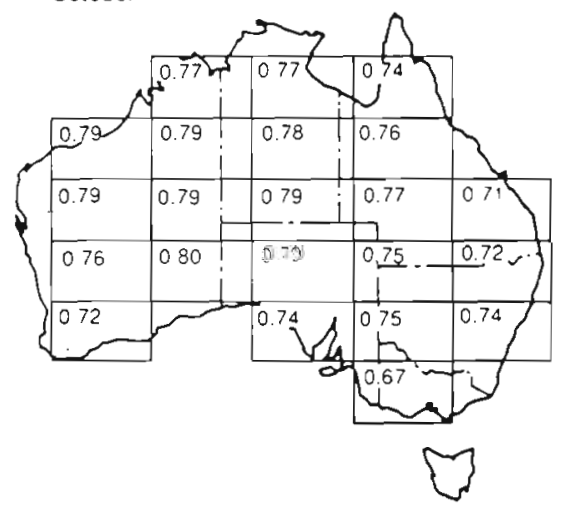

Fig. 9. Modelled values of the ratio of the downward incident solar radiation at the surface to the top-of-the-atmosphere downward solar radiation for January, April, July and October. Values greater than ca 0.7 indicate clear skies 

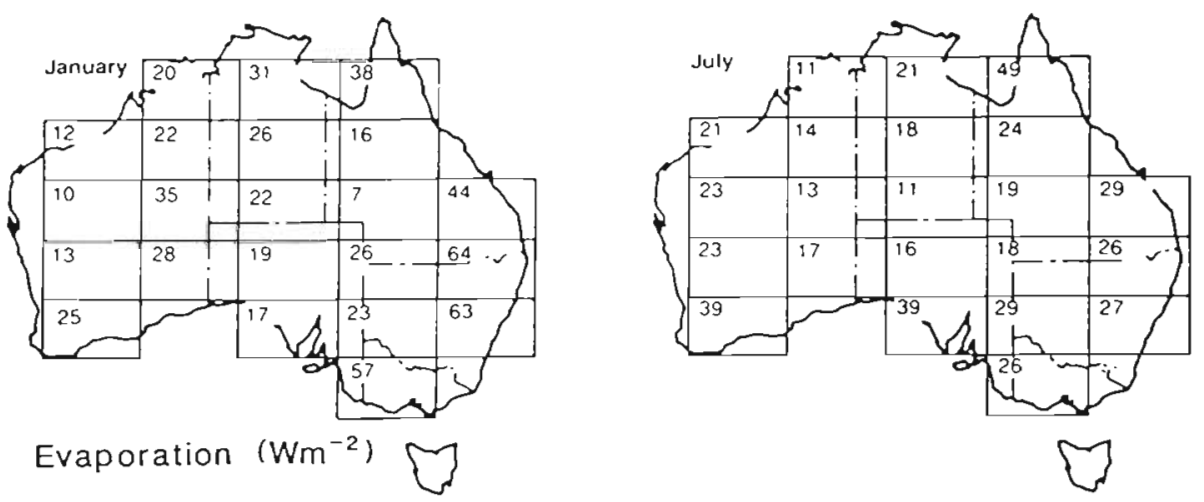

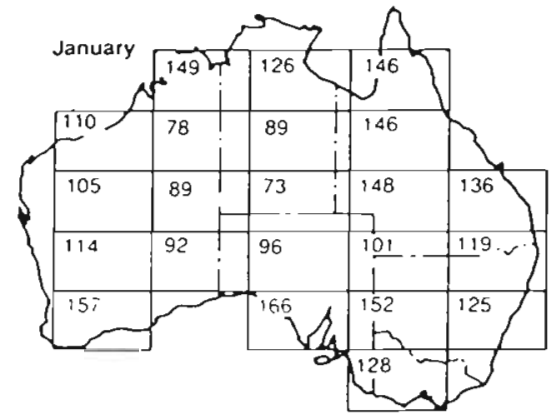

Sensible heat $\left(\mathrm{Wm}^{-2}\right)$

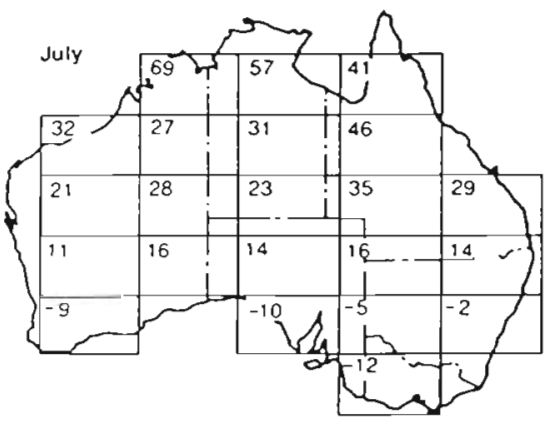

ration and sensible heat fluxes $\left(\mathrm{W} \mathrm{m}^{-2}\right)$ for January and July

York, the model's annual total is ca $480 \mathrm{~mm}$ whilst observations in the peninsula are greater than $700 \mathrm{~mm}$.

Fig. 12 shows histograms of modelled monthly rainfall totals. The seasonality is fairly well captured by the model except in the south, around Melbourne, where the model shows a considerable seasonal cycle which is not seen in the observations. The pattern of overestimation in the desert and underestimation near the coasts is, of course, repeated in the monthly values so that the very high monthly rainfall total in e.g. Darwin are not simulated in the model.

Overall, the gross rainfall regime is resonably well captured but the coarse resolution of the model grid means that low rainfall regimes are too wet and the narrow coastal areas with relatively high rainfalls are too dry. This resolution problem would make the predictions of models of such coarse resolution very hard to use for agricultural planning.

Two grid areas only have precipitation falling as snow rather than as rain in 1 or 2 winter months and the monthly averaged amounts are very small. Of the 2 areas (shaded in Fig. 12) the more northern area has monthly mean amounts of snow recorded for May and June of $6 \times 10^{-6}$ and $4.6 \times 10^{-4} \mathrm{~mm}$ water equivalent. The more southern of the grid areas has snow recorded only in May, a monthly mean amount of $3 \times 10^{-6} \mathrm{~mm}$ water equivalent. The present average lower altitude limit for cross-country sking in New South Wales is about $1500 \mathrm{~m}$. There is usually only a 2 mo season with an available area of about $1400 \mathrm{~km}^{2}$ (Galloway 1988). If the depth of the snow is taken as between $0.5 \mathrm{~m}$ and 1 $\mathrm{m}$ (i.e. a water equivalent depth of 50 to $100 \mathrm{~mm}$ ) the water-equivalent volume of snow for 1 mo in New South Wales is between $0.7 \times 10^{8}$ and $1.4 \times 10^{8} \mathrm{~m}^{3}$. This is ca 3 orders of magnitude greater than the mean monthly snow cover predicted in the model which is roughly $\left(4.5 \times 10^{5}\right) \times\left(7.5 \times 10^{5}\right) \times 4.6 \times 10^{-7} \mathrm{~m}^{3}$ i.e. ca $1.5 \times 10^{5} \mathrm{~m}^{3}$ of water equivalent snow.

The annual values of total runoff follow the rainfall regimes and, in the real world, the orography. Therefore the model overestimates runoff in the centre of the continent and underestimates runoff on the east coast (Fig. 13). Fig. 13a, b compare the simulated and observed annual total runoff $(\mathrm{mm})$. Direct comparison can be drawn between the depth of water equivalent to the annual catchment drainage' (Fig. 13b) and the grid area totals in Fig. 13a. Thus the southeast coast run-off of $144 \mathrm{~mm}$ compares with the simulated total of $108 \mathrm{~mm}$. Simulations in the Gulf of Carpentaria (central north) also compare fairly well with observations as do those for the area of the Murray/Darling Basin. The seasonality in the modelled total runoff is shown in Fig. $13 c$, d. On the east coast there is very little seasonality but the west coast shows a large seasonal signal. There 

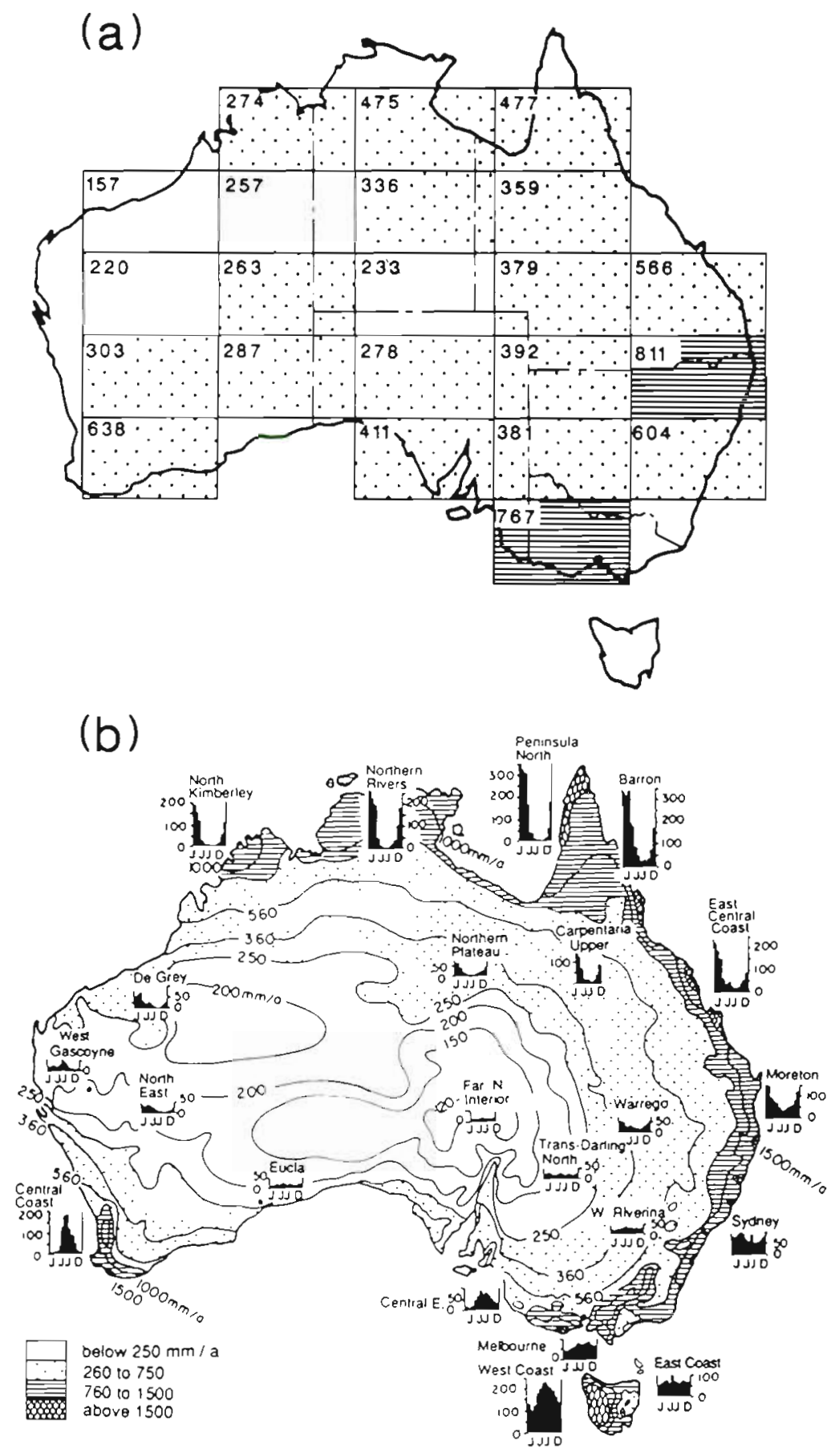

Fig. 11. (a) Modelled total annual rainfall $(\mathrm{mm})$. (b) Observed annual totals of rainfall (mm) and monthly values (mm) as histograms for selected locations (after Linacre \& Hobbs 1977)

appears to be an anomaly in the desert grid element in the centre of the continent where there is a very large runoff of ca $7 \mathrm{~mm}$ for the month of January.

Total soil moisture has been identified as an important parameter in determining land surface climate. Although this parameter cannot be measured readily at a scale appropriate to GCMs, studies by Mintz \& Serafini (1987) and Serafini (1986) evaluated it for input to
GCMs. The spatial resolution selected by Serafini (1986) was $4 \times 5^{\circ}$; their computations used the Thornthwaite model (e.g. Thornthwaite \& Holzman 1939, Thornthwaite 1948). Great care must be taken in comparing different model estimates of soil moisture. The Serafini (1986) data are essentially of a bucket-type surface hydrology and thus their values relate to water depths in such a bucket scheme; the maximum ground 
Fig. 12. Histograms of modelled monthly totals of rainfall $(\mathrm{mm})$ for selected grid elements. (The 2 stippled grid elements have very small snowfalls in early winter as described in the text)

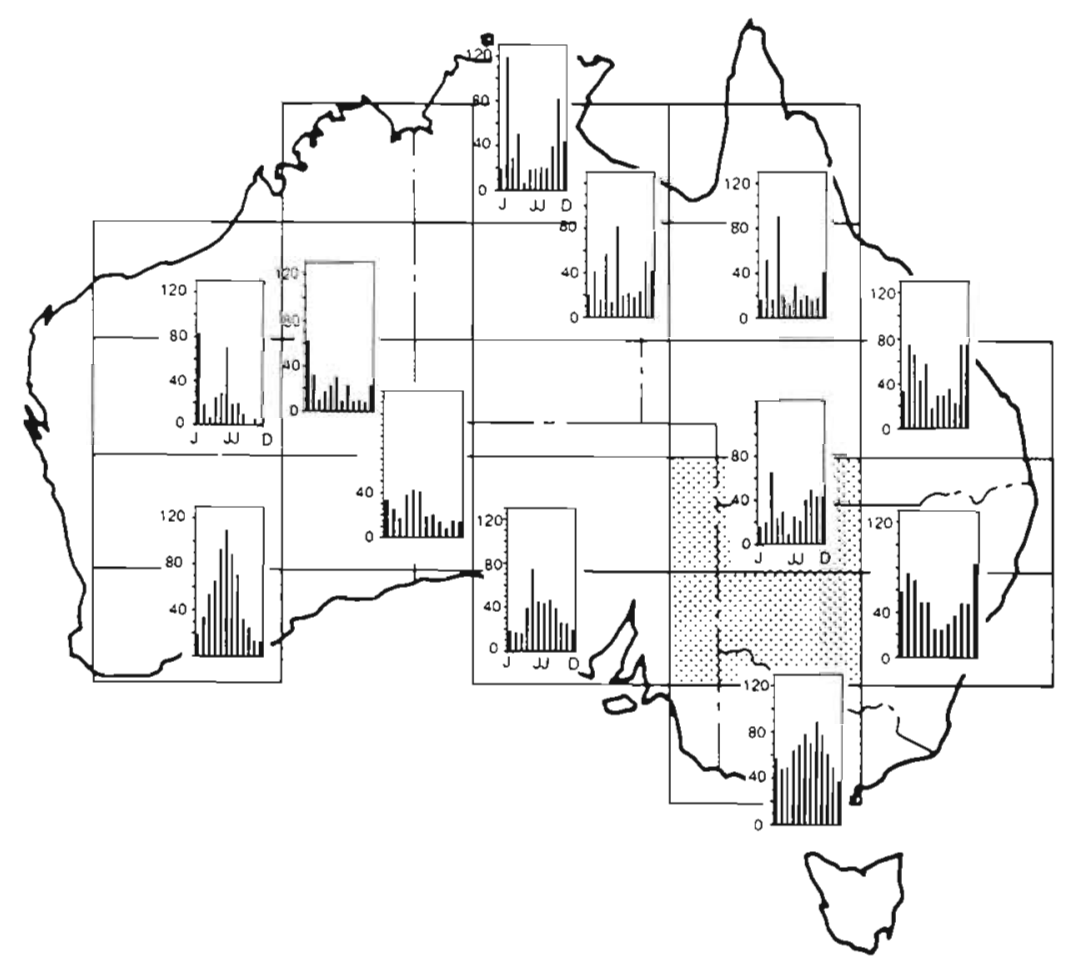

east but values agree roughly in July and October for the Melbourne area grid box. The major disagreement is over the semi-arid and arid two-thirds of the continent. Serafini (1986) give zero soil moisture for this area for almost the whole year whilst the BATS comparative moisture values are typically around $20 \mathrm{~mm}$ and can be as large as $37 \mathrm{~mm}$ in the central semi-desert boxes. It must be recalled, however, that these differences are relatively small compared to the maximum possible soil moisture amounts which are between 360 and $480 \mathrm{~mm}$ for the BATS scheme and, presumably, associated with 'bucket depths' of 100 to $150 \mathrm{~mm}$ in other GCMs. Moreover in the BATS scheme this area is classed as desert or semi-desert (see Fig. 2) and thus there is little or no vegetation (zero in the desert box and a maximum of $10 \%$ cover in the semi-desert boxes, from Table 2); the total evapotranspiration will be predominantly due to evaporation of this 'deep' soil moisture and will therefore be small.

At the continental scale the values of Serafini (1986) seem more plausible than those of BATS but the former are very coarse being essentially zero for two-thirds of the continent and between 100 and $150 \mathrm{~mm}$ (maximum possible) in the east and southeast. The very large differences between the BATS total soil moisture and the comparative soil moisture underline that great care must be taken in attempting to initialize a range of land surface schemes coupled into GCMs using any 'agreed' data set which may have been constructed on the basis of different parameterizations.
BATS + CCM values for comparative soil moist are smaller than those of Serafini in the east and south- 
(a) Annual total runoff $(\mathrm{mm})$

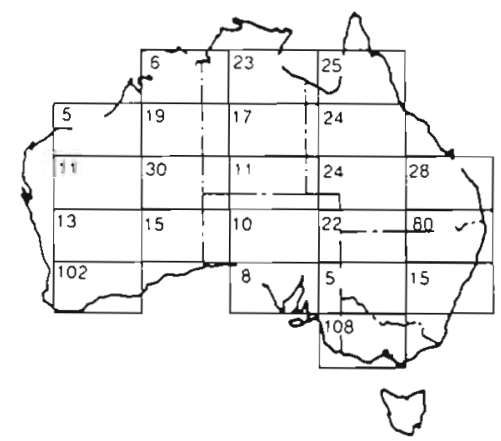

(b)

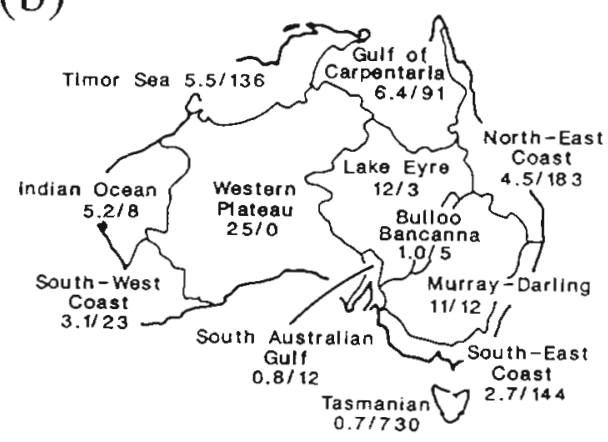

(c) Total runoff $\left(\mathrm{mm} d^{-1}\right)$

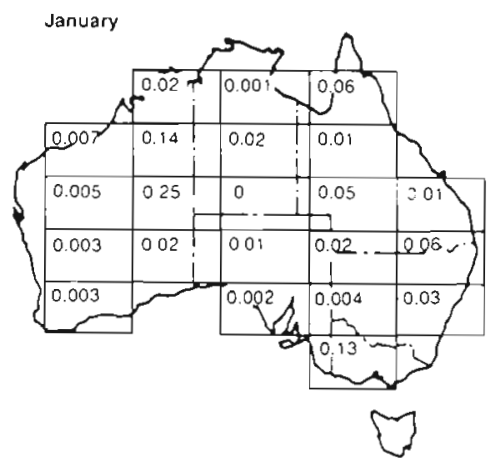

(d)

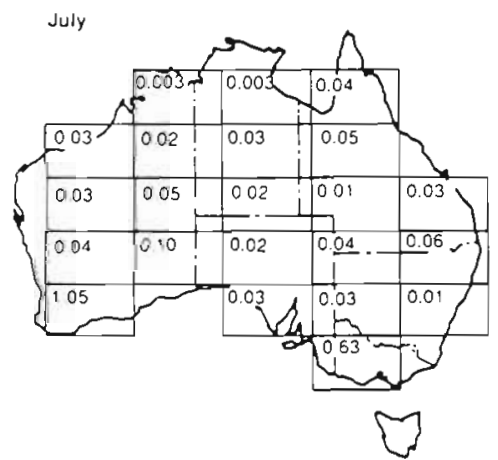

\section{SUMMARY AND FUTURE OF EVALUATIONS OF LAND SURFACE CLIMATE COMPUTATIONS}

Growing concern about predicted changes to the climate have focussed attention upon the need for improvements in the parameterization of the land surface climate. It is not straightforward to evaluate the performance of the new generation of land surface schemes which are currently being developed and coupled into climate models. One such scheme is the Biosphere Atmosphere Transfer Scheme, which is used in conjunction with the NCAR Community Climate Model. Previously the performance of this scheme has been tested in a 'stand-alone' mode with prescribed atmospheric forcing and also in a vegetation change simulation (tropical deforestation). An alternative method of evaluation of the performance of such schemes is by analysis at a regional scale of the land surface climate predicted by the GCM when coupled to such a scheme. This has been undertaken here for continental Australia.

The results of a $3 \mathrm{yr}$ integration of BATS + CCM1 demonstrate that the general circulation in the Australasian region is adequately simulated with the movement of the ITCZ and the associated switch between tradewind monsoon and prevailing westerly regimes being well captured. Consideration of a preliminary pseudo-vegetation index constructed from surface radiative fluxes computed in BATS and the values of planetary albedo emphasise the importance of inter-comparison between satellite data and the results of such land surface/GCM coupled models.

The major inconsistencies in the BATS simulation are associated with the surface hydrology. Precipitation is too high in the central desert area and the large maxima of rainfall on the coast are grossly underestimated. This may be entirely a result of the coarse resolution of the GCM grid but, since rainfall is of crucial importance to agricultural and water supply activities, the inconsistencies clearly merit further consideration. Total runoff is modified by orography in the real world and is generally measured at a catchment scale. Intercomparisons with the highly simplistic runoff amounts calculated as scalars, rather than vectors, in schemes such

Fig. 13. (a) Annual total (surface + subsuriace) model runoff (mm). (b) Annual drainage from the major catchments in Australia. Numbers give the area (in units of $100000 \mathrm{~km}^{2}$ ) and the depth of water $(\mathrm{mm})$ equivalent to the annual catchment drainage (after the Australian Water Resources Council 1975 and Linacre \& Hobbs 1977). [Compare the second value, water depth, with the totals in (a) J. (c), (d) Modelled January and July runoff ( $\mathrm{mm} \mathrm{d}^{-1}$ ) 
(a) Normalized Soil Water
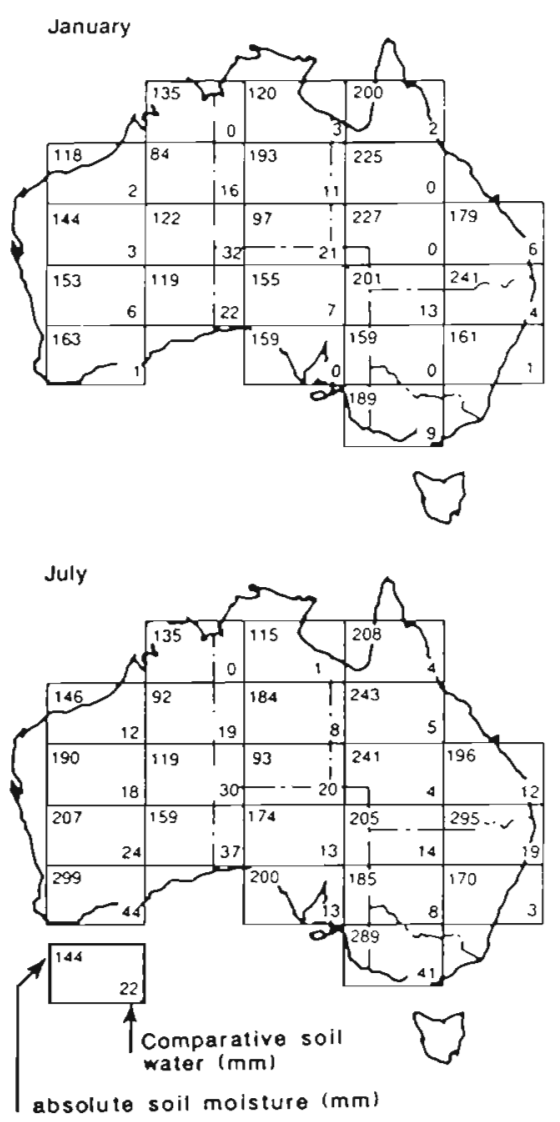

Fig. 14.(a) Modelled total soil water $(\mathrm{mm})$ and comparative soil water for January, April, July, October (normalized). The comparative value is obtained by subtracting the below-plantwilting moisture from the total moisture, dividing by the maximum possible soil moisture for BATS in that location and normalizing for comparison by multiplying by $150 \mathrm{~mm}$ to place values in the same range as Serafini (1986). (Note that for 2 grid-squares the subtraction of below-plant-wilting moisture gives the value $-1 \mathrm{~mm}$. These have been shown as zero). (b) Soil water (normalized) for January, April, July and October $(\mathrm{cm})$ from Serafini (1986)

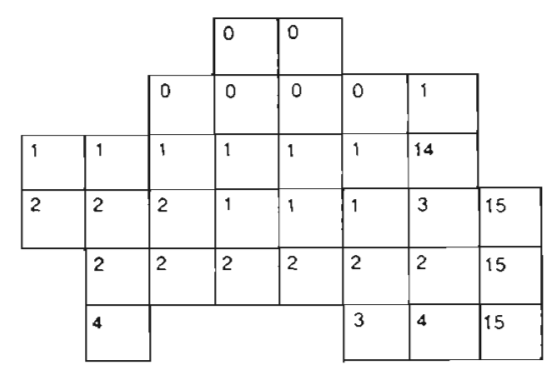

(b) Normalized Soil Water

January
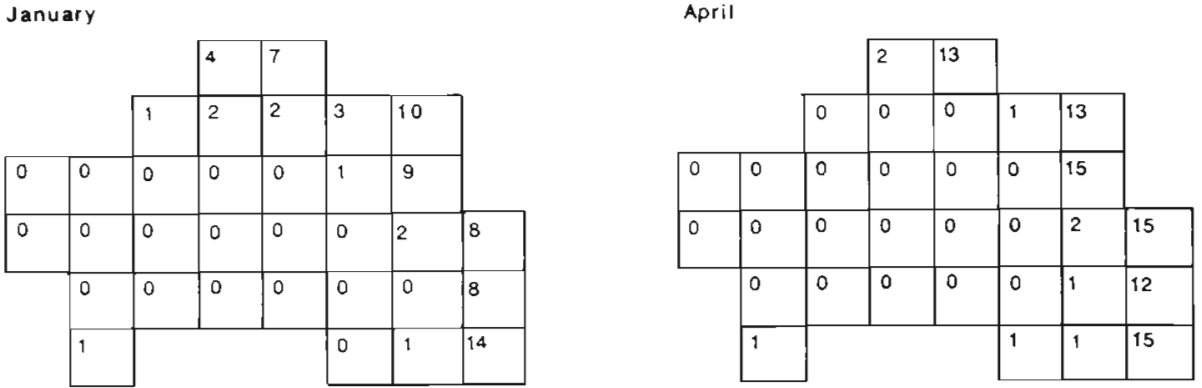

July

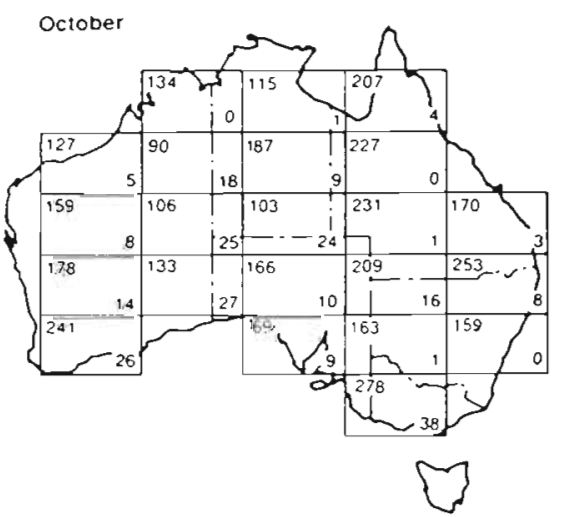

October

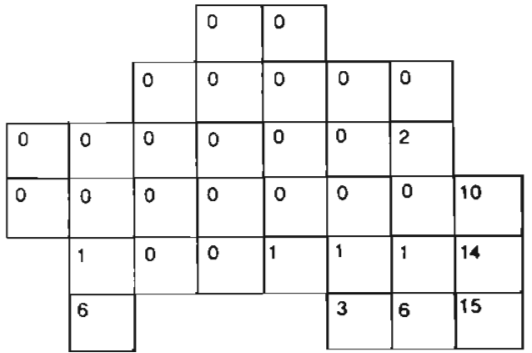


as BATS is difficult. Generally the total runoff pattern follows the precipitation pattern, being too large in the central desert region with an extreme seasonal signal shown here and too small near the coast. Further problems associated with the surface hydrological regime include the difficulty of comparing total modelled evapotranspiration with evaporation calculated from evaporation pan measurements. In a semi-arid to arid environment such as Australia the latter are gross overestimates. In the semi-arid and desert regions, the BATS scheme gives rise to generally larger comparative soil moistures than those recently calculated for input to GCMs by Serafini (1986) although the differences were less than $20 \%$ of the total soil water possible. In the coastal regions the relationship tended to be reversed as Serafini (1986) recorded up to $150 \mathrm{~mm}$ while BATS does not achieve comparative soil moistures greater than $50 \mathrm{~mm}$. Clearly care must be taken in initialization of new land surface schemes from, for example, an agreed data set, since surface (and atmospheric) climates are known to be highly sensitive to hydrological initializations. This warning is especially important for short period (months) simulations because surface and sub-surface hydrological regimes are likely to take longer than this to come into equilibrium with the forcing climate model (Hunt 1985, Wilson et al. 1987a).

More minor differences between the BATS climate and measurements are confined to the central desert area and the crop and short grass regions in the south. Maximum temperatures are too high in the desert and minimum temperatures marginally too high in the southeast. Surface net radiation appears to be underestimated in the desert by up to $50 \mathrm{~W} \mathrm{~m}^{-2}$ (probably due to the combined effect of overestimated temperatures and, more importantly, overestimated cloud amounts). Some of these secondary inconsistencies could be partially the result of the poor simulation of the surface hydrological regimes which seems likely to be primarily the fault of the coarse spatial resolution of the model.

There are 2 important conclusions which can be

Average planetary albedo at top of atmosphere
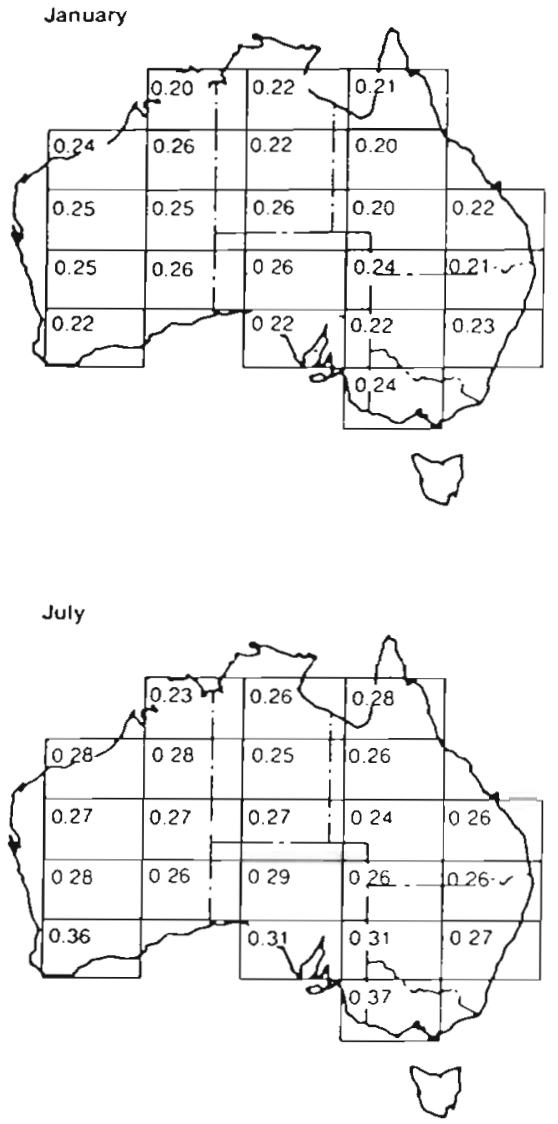

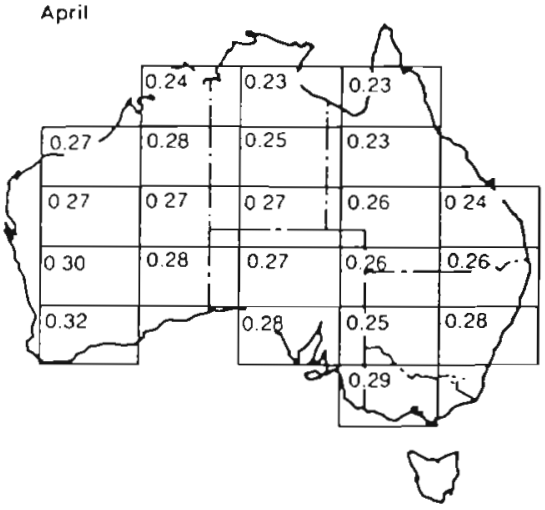

October

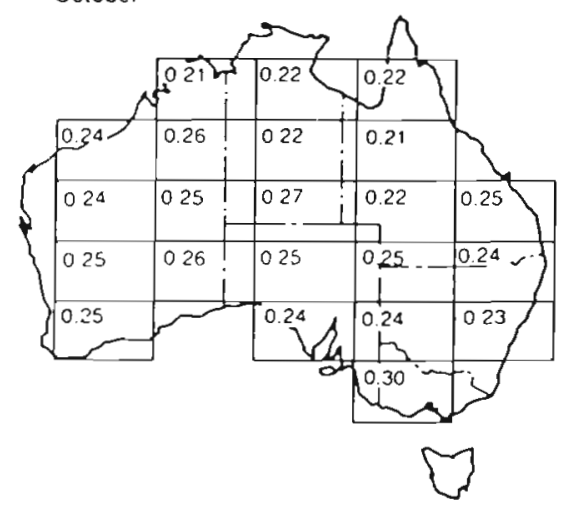

Fig. 15. Modelled planetary (i.e. top-ot-the-atmosphere) albedos for January, April, July, October 
drawn from this analysis: in areas of complex topography which have spatial extents significantly smaller than the GCM resolution the predicted precipitation patterns and intensities are poor, and secondly the best method of validation of land surface climatic features generated at the GCM scale may not necessarily be by comparison with conventional meteorological measurements.

Some preliminary suggestions have already been made about improving validation tests for GCM predictions such as those considered here. One proposal is to compute a model-generated vegetation index which would be comparable with the NOAA satellite-derived global vegetation index (GVI) if suitable visible and near-infrared surface reflectivities are specified for all soils and vegetation types. Examination of the modelled and satellite-measured GVI over a seasonal cycle would permit identification of areas where specified land surface parameters fail to simulate reality

A second, and more complete, test parameter which is readily comparable with satellite data is the planetary (or top-of-the-atmosphere) albedo. Fig. 15 shows the computed values of the planetary albedo for the model. It has a maximum in July over most of the continent and a minimum for most areas in January. The greatest seasonality, which is likely to be due to variations in cloud amount, occurs in the southeast and southwest. The near uniformity of planetary albedo over the whole continent is the result of high surface albedos in the desert and some cloud cover (cf. Fig. 9) in the tropical north and mediterranean south climates.

A more sensitive test of the adequacy of modelled surface climate would be to compare the computed diurnal variation in the skin temperature with a similar value derived from satellite data. Fig. 16 shows the 12 mo mean values of this skin temperature difference as predicted by BATS + CCM1. The skin temperatures are computed within the BATS routine by multiplying the computed leaf temperature by the vegetation fraction in the grid square and adding to this the product of the soil surface temperature and the non-vegetated surface fraction. The diurnal difference is the averaged daytime values minus the averaged night-time value. Generally the greatest skin temperature difference occur in January (summer) and the smallest in July (winter). Fig. 16 could form the basis of a model/ satellite intercomparison that would focus on both weaknesses and strengths of the presently modelled regime.

In regions where the atmospheric dynamical and physical forcings vary on a scale smaller than a few hundred kilometres, the use of currently available GCMs is inadequate to describe the details of the climatic patterns. Important features of the Australian land surface climate are relatively poorly simulated by current GCMs, partly because the orographic features which control much of the near-coastal climate are unrealistically smooth at grid scales of current GCMs. A factor of 10 or more increase in the horizontal resolution may be required in order to capture regional scale climate features. Recently it has been proposed that some of the problems of inadequate prediction of precipitation and hence surface hydrology could be overcome if limited area models were embedded in GCMs.

The effect on the modelled topography is illustrated by Fig. 17 which compares the orography as represented in the CCM1 (R15 version) used in these simulations with the representation of orography in a $50 \times 50 \mathrm{~km}$ grid prepared for a limited area or mesoscale numerical model (LAM). These LAMs are very costly in computational resources and therefore cannot be used for the multiyear simulations required for climate simulation. However, Giorgi et al. (1989) have shown that driving a LAM with regional-scale forcing from a GCM can produce considerable improvements in the simulation of both spatial distribution and intensity of rainfall in regions of complex orography. They studied the western United States where the Rocky and Sierra Nevada Mountains contain the Great Basin. Improving the orographic representation (as is clearly the case in Fig. 17) can considerably improve shortterm (days to a month) prediction of precipitation patterns. The problem then emerges of extrapolating from the few individual storms which can be computed using the LAM embedded in the GCM to the annual rainfall regime. This may be more readily undertaken in areas, such as much of Australia, where large, individual storms dominate monthly rainfall statistics.

Overall, this study has underlined the urgent need for an integrated (i.e. models and satellites) approach to improving the simulation of the land-surface climate. In a similar vein, Dickinson (1987, p.7) states that "The need to develop such a scheme for analysis and application of the satellite data should be the basic paradigm upon which future observing systems of the land system are designed. ... Unfortunately, there does not now seem to be any research community prepared to develop the required global data sets or to carry out the needed numerical simulations." Whilst this lack of awareness and readiness within the climate community is, indeed, to be bemoaned, the study reported here has demonstrated that it would be both possible and beneficial to initiate such integrated studies at the continental scale.

Acknowledgements. I thank Dr R. E. Dickinson for providing the surface climatology from a 3 yr integration of the NCAR CCM1 and Patrick Kennedy for considerable assistance in data transmission. Dr A. Pitman commented constructively on an earlier version of the manuscript. This work was supported by a grant from the Australian Research Council. 
Skin temperature difference (Tday-Tnight) $\left({ }^{\circ} \mathrm{C}\right)$
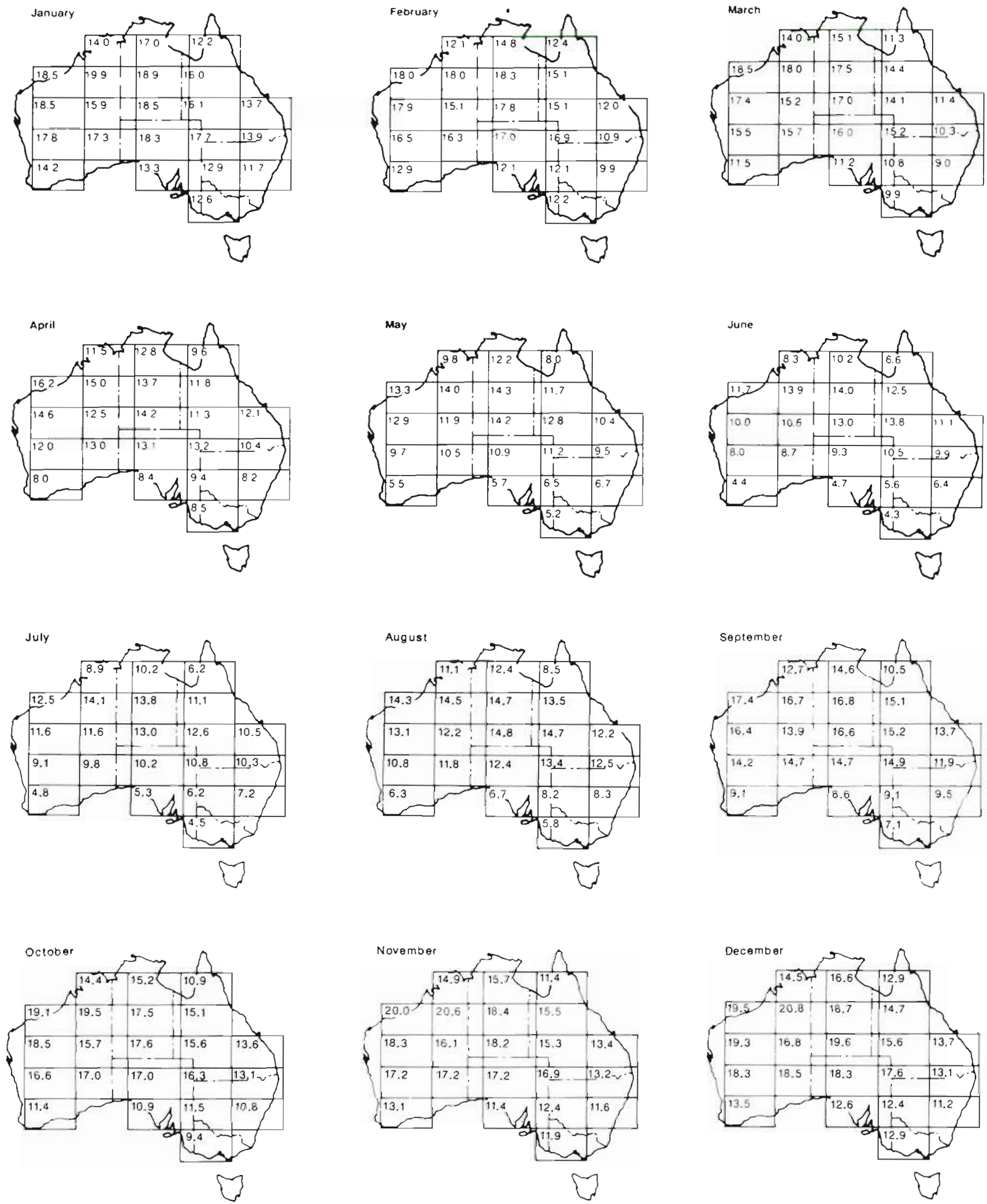

Fig. 16. Modelled monthly mean values of daytime - night-time surface skin temperature differences $\left({ }^{\circ} \mathrm{C}\right)$ 
Fig. 17. (a) CCM1 (R15 grid) elevation $(\mathrm{m})$ in the Australian region. Note the maximum elevation $(390 \mathrm{~m}$ ) lies midway between 2 real peaks in Western Australia. (b) Limited area mesoscale model with a $50 \mathrm{~km}$ grid elevation $(\mathrm{m})$ captures the western peaks much more realistically; also the eastern coastal ranges with the Blue and Snowy Mountain areas having elevations of 940 and $1142 \mathrm{~m}$ respectively

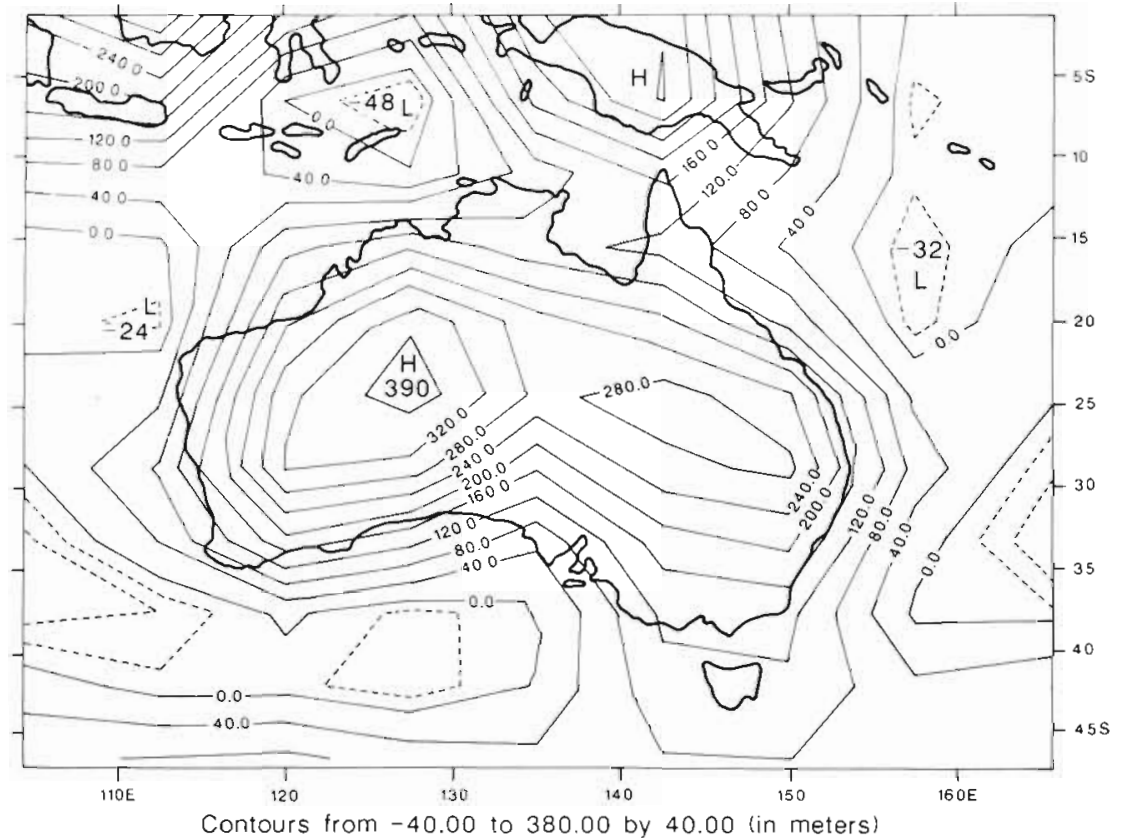

b Higher $(50 \mathrm{~km})$ resolution

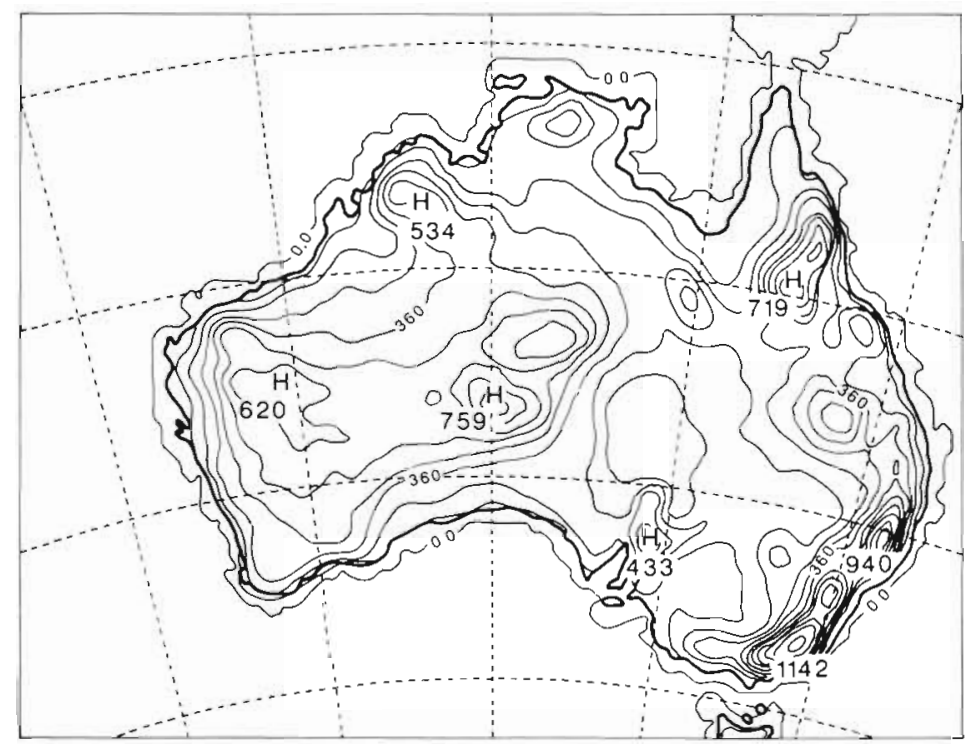

\section{LITERATURE CITED}

Australian Water Resources Council (1975). Ground-water resources of Australia, Dept Env. \& Cons., Canberra

Bourke, W., McAvaney, B., Puri, K., Thurling, R. (1977). Global modeling of atmospheric flow by spectral methods. In: Chang, J. (ed.) Methods in computational physics, general circulation models of the atmosphere, Vol. 17. Academic Press, New York, p. 267-324

Clapp, R. B., Hornberger, G. M. (1978). Empirical equations for some soil hydraulic properties. Water Resour. Res. 14 $601-604$

Dickinson, R. E. (1984). Modeling evapotranspiration for three-dimensional global climate models. In: Climate processes and climate sensitivity. Geophysical Monograph 29, American Geophysical Union, Maurice Ewing Vol. 5, Washington, D.C., p. 58-72

Dickinson, R. E. (1987). Modeling land-surface processes and hydrology for global climate simulations: a modeler's view of the GEWEX concept, Appendix K. In: Report of the workshop on space systems possibilities for a global energy and water cycle experiment. World Climate Programme, WCP-137, WMO/TD - No. 180, WMO, Geneva, p. 58-69

Dickinson, R. E., Henderson-Sellers, A. (1988). Modelling tropical deforestation: a study of GCM land-surface parameterizations Q. J. R. Meteor. Soc. 114(B): 439-462 
Dickinson, R. E., Henderson-Sellers, A., Kennedy, P., Wilson, M. F. (1986). Biosphere-Atmosphere Transfer Scheme (BATS) for the NCAR Community Climate Model. NCAR Tech. Note, NCAR/TN-275+STR, Boulder, Colorado

Division of National Mapping (1986). Atlas of Australian resources, Vol. 4, Climate. Nat. Map. Canberra

Galloway, R. W (1988). The potential impact of climate changes on Australian ski fields. In: Pearman, G. I. (ed.) Greenhouse: planning for climate change. CSIRO, Canberra, p. 428-437

Gentilli, J. (1968). Sun, climate and life. Jacaranda Press, Sydney

Giorgi, F., Bates, G. T., Errico, R. M., Dickinson, R. E. (1989). Modeling the climate of the western U.S. with a limited area model coupled to a general circulation model. In: Workshop on climate and agriculture. AMS Pubn., Charleston, S. Carolina, p. 201-208

Hunt, B. G. (1985). A model study of some aspects of soil hydrology relevant to climatic modelling, Q. J. R. Meteor. Soc. 111. 1071-1085

Linacre, E., Hobbs, J. (1977). The Australian climatic environment. Wiley, Chichester

Matthews, E. (1983). Global vegetation and land use: new high resolution databases for climate studies. J. Clim. appl. Meteor. 22: 474-487

Mintz, Y., Serafini, Y V (1984). Global fields of monthly normal soil moisture as derived from observed precipitation and an estimated potential evapotranspiration. In: Baer, F., Mintz, $Y$ (eds.) Land surface influences on weather and climate. Final Tech. Rep. NASA-CR-173575, Washington, D.C.

Olson, J. S., Watts, J. A., Allison, L. J. (1983). Carbon in live vegetation of major world ecosystems. DOE/NBB Report No. TR004, Oak Ridge National Laboratory, Oak Ridge, TN 37830

Paltridge, G. W. (1975). Net radiation over the surface of Australia. Search 6:37-39

Pitman, A. J. (1989). A new land-surface scheme for use in general circulation models, Ph. D. thesis, Univ. Liverpool

Sellers, P. J., Mintz, Y., Sud, Y C., Dalcher, A. (1986). A simple

Editor: Dr G. Esser biosphere model ( $\mathrm{SiB}$ ) for use within general circulation models. J. Atmos. Sci. 43: 505-531

Serafini, Y V (1986). Modélisation de l'interface sol-atmosphère en utilisant des données conventionelles et satellitaires; impact climatique à grand échelle. Thèse de Docteur ès Sciences, Université Pierre et Marie Curie, Paris

Sinden, J. (ed.) (1972). The naturat resources of Australia. Angus \& Robertson, Sydney

Thomas, G., Henderson-Sellers, A. (1987). Evaluation of satellite derived land cover characteristics for global climate modelling. Climatic Change 11: 313-347

Thornthwaite, C. W. (1948). An approach towards a rational classification of climate. Geog. Rev. 38: 55--94

Thornthwaite, C. W., Holzman, B. (1939). The determination of evaporation from land and water surfaces, Mon. Wea. Rev. 67: 4-11

Tucker, C. J., Townshend, J. R. G., and Goff, T E. (1985). African land-cover classification using satellite data. Science 227: 369-375

Williamson, D. L., KiehI, J. T., Ramanathan, V., Dickinson, R. E., Hack, J. J. (1987). Description of NCAR Community Climate Model (CCM1), NCAR Tech. Note, NCAR/ TN-285+STR, NCAR, Boulder, Colorado

Williamson, D. L., Williamson, G. S. (1987). Circulation statistics from seasonal and perpetual January and July simulations with the NCAR Community Climate Model (CCM1): R15, NCAR Tech. Note, NCAR/TN-302+STR, NCAR, Boulder, Colorado

Wilson, M. F. Henderson-Sellers, A. (1985). A global archive of land cover and soils data for use in general circulation climate models. J. Clim. 5: 119-143

Wilson, M. F., Henderson-Sellers, A., Dickinson, R. E., Kennedy, P. J. (1987a). Sensitivity of the biosphere-atmosphere transfer scheme (BATS) to the inclusion of variable soil characteristics. J. Clim. appl. Meteor. 26: 341-362

Wilson, M. F., Henderson-Sellers, A., Dickinson, R. E. Kennedy, P. J. (1987b). Investigation of the sensitivity of the land-surface parameterization of the NCAR Community Climate Model in regions of tundra vegetation. J. Climatol. 7: $319-343$

Manuscript first received: September 25, 1989

Revised version accepted: May 3, 1990 